\title{
LA DIMENSIÓN CONSTITUCIONAL DE LAS INSTITUCIONES NACIONALES DE DERECHOS HUMANOS
}

\author{
THE CONSTITUTIONAL DIMENSION OF NATIONAL HUMAN \\ RIGHTS INSTITUTIONS
}

\author{
VICENTE AYLWIN FERNÁNDEZ* \\ ALBERTO CODDOU MC MANUS**
}

\section{RESUMEN}

Este trabajo aborda la dimensión constitucional de las instituciones nacionales de derechos humanos. En el marco del actual proceso constituyente chileno, el artículo analiza las principales preguntas constitucionales que pueden surgir respecto a la institucionalidad de derechos humanos en Chile, con especial énfasis en la posición y el rol que debiera jugar el actual Instituto Nacional de Derechos Humanos en el futuro orden constitucional. Para ello, y después de analizar la pregunta sobre una eventual autonomía constitucional para una institución nacional de derechos humanos, el artículo reflexiona sobre las principales opciones o posibilidades regulatorias: modelo unipersonal o colegiado; concentración o fragmentación de instituciones; y discusiones generales sobre sus atribuciones. Finalmente, el trabajo realiza una propuesta de regulación constitucional de la institución nacional de derechos humanos.

\footnotetext{
*Abogado, Universidad Diego Portales. Doctorando y Máster en Derecho, Universidad Pompeu Fabra, Barcelona, España. Correo: vicente.aylwin@mail.udp.cl. ORCID: https://orcid.org/0000-0002-91480016 .

**Doctor en Derecho, University College of London, Reino Unido. Profesor Instituto de Derecho Público, Universidad Austral de Chile, Valdivia, Chile. Correo: alberto.coddou@uach.cl. ORCID: https://orcid.org/0000-0003-2041-2304.
}

Trabajo recibido el 18 de agosto de 2021, y aprobado para su publicación el 20 de diciembre de 2021. 
Palabras clave: Instituciones nacionales de derechos humanos, Proceso constituyente chileno, Autonomía constitucional, Instituto Nacional de Derechos Humanos, Defensoría de la Niñez, Derechos humanos.

\section{ABSTRACT}

This work addresses the constitutional dimension of national human rights institutions. Within the current constituent process in Chile, the article analyses the main question that may arise regarding the institutional framework for human rights protection in Chile, with a special emphasis in the position and role that should play the current National Human Rights Institution (INDH). In order to do that, and after addressing the question regarding its constitutional autonomy, the article ends up with the regulatory choices: unipersonal or collegiate bodies; concentration or fragmentation of institutions; and general debates about its powers. Finally, the article proposes a specific constitutional regulation for a new national human rights institution.

Keywords: National human rights institutions, Chilean constituent process, Constitutional autonomy, National Human Rights Institute, Ombudsman for Children, Human rights.

\section{INTRODUCCIÓN}

Las instituciones nacionales de derechos humanos (en adelante, INDHs), descritas como aquellas "instituciones con un mandato legal o constitucional de proteger y promover derechos humanos", se han transformado en actores principales para mejorar la efectividad de los derechos humanos, acortando la brecha que existe entre los estándares internacionales de derechos humanos y el impacto real que estos tienen en la vida de las personas. ${ }^{1}$ En este escenario, se han avanzado diversas

\footnotetext{
${ }^{1}$ Programa de las Naciones Unidas para el Desarrollo (PNUD); Oficina del Alto Comisionado de las Naciones Unidas para los Derechos Humanos (ACNUDH), "UNDP-OHCHR Toolkit for collaboration with National Human Rights Institutions", 2010, https:/www.ohchr.org/Documents/Countries/ NHRI/1950-UNDP-UHCHR-Toolkit-LR.pdf, consultada: 15 de julio de 2020.
} 
ideas sobre su mejor configuración/diseño institucional y sobre su impacto práctico. En el marco del proceso constituyente chileno, surgirán diversas reflexiones sobre la arquitectura institucional del Estado, entre ellas, la posición que ocupará el conjunto de entidades u órganos que forman parte de la "institucionalidad de derechos humanos", con especial énfasis en la posición y el rol que eventualmente ocupará el Instituto Nacional de Derechos Humanos (en adelante, INDH-CHI) u otra institución equivalente. En este escenario, surgen diversas preguntas, que refieren tanto a cuestiones constitucionales como de diseño institucional: ¿es la institucionalidad de derechos humanos un tema de relevancia constitucional o que concierne a un debate constitucional? ¿es necesario garantizar la autonomía constitucional de la institución nacional de derechos humanos? ¿cómo pensar en una institucionalidad de derechos humanos en relación con las funciones públicas que está destinada a cumplir y los diversos modelos de apertura constitucional hacia el derecho internacional de los derechos humanos? ¿puede una determinada configuración mejorar el rendimiento de la institucionalidad de derechos humanos?

Considerando estas preguntas, el presente trabajo pretende analizar el modo en que el debate constituyente debiera abordar la discusión sobre la institucionalidad de derechos humanos en Chile, con especial énfasis en la posición y el rol que debiera jugar el INDH-CHI u otra institución equivalente en el futuro ordenamiento constitucional. Para ello, se adoptarán diversas perspectivas para desarrollar insumos adecuados para el debate constituyente, en base a múltiples metodologías. En cuanto a la relación entre diseño y rendimiento institucional, se examinarán los debates provenientes del derecho y las ciencias políticas, con especial consideración del funcionamiento de INDHs a nivel comparado. Para responder la pregunta sobre la relevancia constitucional de este tema, se considerarán debates de teoría constitucional acerca del concepto y funciones de una constitución, así como diversas reflexiones en torno a la necesidad de que ciertas cuestiones sean o no incluidas en una constitución, que derivan de estudios de ciencia política o de análisis institucionales del derecho acerca del rol que juegan las instituciones independientes en un orden constitucional determinado. Además, estas preguntas suponen ofrecer al lector una descripción profundizada y un análisis de la formación y desarrollo de la institucionalidad de derechos humanos en Chile, así como una visión panorámica acerca de los primeros diez años de funcionamiento del INDH-CHI. Finalmente, se 
ofrecerá una propuesta de regulación constitucional de la INDH que puede servir como punto de partida para el debate constituyente que eventualmente pueda tener lugar al respecto.

\section{LAS INSTITUCIONES NACIONALES DE DERECHOS HUMANOS}

\section{Definición, función y estándares aplicables}

Las INDHs adoptan múltiples formas y varían en cuanto a su composición, atribuciones y ubicación dentro de la institucionalidad estatal. Sin embargo, todas ellas parten de la misma premisa: el mero reconocimiento jurídico de los derechos humanos no implica su efectiva realización, razón por la cual se requiere una institucionalidad cuya tarea sea promoverlos y protegerlos en la práctica. ${ }^{2}$ La idea que subyace a la creación de INDHs es la de supervisar la conducta de los poderes estatales de acuerdo con los estándares nacionales e internacionales de derechos humanos. Según el derecho internacional de los derechos humanos (DIDH), las INDHs se caracterizan por ser organismos independientes y especializados que tienen el mandato constitucional o legislativo de promover y proteger los derechos humanos mediante la supervisión de los órganos públicos, la educación y difusión de una cultura de derechos humanos y, en algunos casos, la posibilidad de recibir denuncias, investigarlas y/o sancionarlas. Esta definición, a grandes rasgos, recoge los lineamientos que ofrecen los estándares internacionales pertinentes, consolidados en los "Principios de París". ${ }^{3}$ A nivel internacional, estas instituciones están sujetas a un proceso de acreditación por pares para medir el grado de cumplimiento de los Principios de París y tienen derecho a participar en el Consejo de Derechos Humanos de la Organización de Naciones Unidas (ONU) y otros mecanismos internacionales de derechos humanos, como el Examen Periódico Universal. ${ }^{4}$

\footnotetext{
${ }^{2}$ Livingstone, Stephen; Murray, Rachel, "The effectiveness of National Human Rights Institutions", en: Halliday, S.; Schmidt, P. (Eds.), Human Rights Brought Home: Socio-legal perspectives on Human Rights in The National Context, Hart Publishing, Portland, 2004, p. 137.

${ }^{3}$ Resolución de la Asamblea General de las Naciones Unidas, A/RES/48/134, "Anexo: Principios relativos al estatuto de las instituciones nacionales", 20 de diciembre de 1993.

${ }^{4}$ European Unión Agency for Fundamental Rights, "Strong and Effective National Human Rights Institutions: challenges, promising practices and opportunities", 2020, https://fra.europa.eu/en/
} 
Como señalamos antes, los "Principios de Paris" incluyen una serie de directrices relativas al mandato, composición y atribuciones de las INDHs. En general, prescriben que la independencia de las INDHs sea garantizada por la constitución o la ley, y que estas contemplen una composición pluralista, un mandato lo más amplio posible, poderes de investigación adecuados y un debido respaldo financiero e institucional. Entre las características de diseño, los "Principios de Paris" incluyen recomendaciones fuertes y débiles. Entre las fuertes, se contempla un mandato de promoción del DIDH a nivel doméstico, incluyendo actividades de educación en derechos humanos y de asesoría especializada en el proceso legislativo, y la formación de relaciones internacionales con instituciones similares en otros países, con el sistema universal de derechos humanos de la ONU y sistemas regionales de derechos humanos. Entre las recomendaciones débiles, las más destacables son: i) asegurar el principio de no representación gubernamental; ii) poder de recibir denuncias, y: iii) posibilidad de que las INDH emitan decisiones vinculantes. A pesar de que los "Principios de París" se consideran como el principal instrumento internacional sobre la materia, han sido criticados por no ser lo suficientemente robustos para asegurar la independencia y la efectividad de las INDHs. ${ }^{6}$ Por lo anterior, se han ido desarrollando distintos criterios para el fortalecimiento de las INDHs, los que buscan ir más allá de los "Principios de Paris", como la Declaración de Nairobi (2008), que entregó una serie de directrices tendientes a que las INDHs desempeñen roles de asistencia de víctimas, con especial énfasis en la reparación integral de violaciones de derechos humanos a través de acciones judiciales o de mecanismos de medicación y conciliación. ${ }^{7}$

En el mismo sentido, el Subcomité de Acreditación (SCA) de la Alianza Global de las Instituciones Nacionales de Derechos Humanos (GANHRI), ha efectuado observaciones generales, entregando herramientas interpretativas

publication/2020/strong-effective-nhris; Resolución 5/1 del Consejo de Derechos Humanos, A/HRC/ RES/5/1, 18 de junio de 2007, consultada 14 mayo de 2020.

${ }^{5}$ Linos, Katerina; Pegram, Tom, "The language of compromise in international agreements", International Organization, Vol. 70, N 3, p. 605.

${ }^{6}$ Kumar, Raj, "National Human Rights Institutions: Good Governance Perspectives on Institutionalization of Human Rights", American University International Law Review, 2003, Vol. 19, № 2, p. 292.

${ }^{7}$ Declaración de Nairobi, Novena Conferencia Internacional de Instituciones Nacionales para la Promoción y Protección de los Derechos Humanos, Nairobi, octubre de 2008. https://ohchr.org/ Documents/Countries/NairobiDeclarationSp.pdf, consultada: 8 de abril de 2021. 
e identificando buenas prácticas orientadas a mejorar la eficacia de los "Principios de Paris". 8 Por ejemplo, para reforzar la independencia de las INDHs, sobre todo ante amenazas de golpes de estado o situaciones de emergencia interna, el SCA ha destacado la necesidad de incorporar un proceso de destitución independiente y objetivo, con causales claramente establecidas, y de asegurar funcionarios remunerados a tiempo completo que estén protegidos por eventuales responsabilidades en actos realizados de buena fe en ejercicio de sus funciones. Finalmente, con respecto a las INDHs que tienen mandato para recibir, examinar y/o resolver quejas o denuncias, el SCA ha recomendado incluir las siguientes competencias: recibir quejas formuladas contra actores privados; entregar amplios poderes para conocer en detalle y de primera fuente la información necesaria para actuar eficazmente (por ejemplo, visitar lugares de detención, proteger testigos, etc.); buscar soluciones amistosas o extra-judiciales; enviar antecedentes al sistema judicial; colaborar en el cumplimiento de sentencias judiciales; $y$, en último término, remitir información al gobierno en casos en que una queja presente pruebas de una violación generalizada o sistemática de los derechos humanos. En el mismo sentido, y en cuanto a las relaciones internacionales de las INDHs, tanto el ACNUDH como la Asamblea General de la ONU han reiterado la necesidad de que estas instituciones colaboren y cooperen con los mecanismos del sistema universal y de los sistemas regionales de derechos humanos para mejorar la implementación de los estándares internacionales a nivel interno. ${ }^{9}$

\section{Modelos}

Existen diversos modelos de INDHs que pueden ser compatibles con los estándares internacionales señalados anteriormente. ${ }^{10}$ De acuerdo con el modelo "Comisión de Derechos Humanos", las INDHs son un órgano colegiado de carácter fundamentalmente consultivo, cuya función es observar

\footnotetext{
${ }^{8}$ GANHRI, Observaciones generales del Subcomité de Acreditación, 21 de febrero de 2018. https:// www.ohchr.org/Documents/Countries/NHRI/GANHRI/SP_GeneralObservations_Revisions_ adopted_21.02.2018_vf.pdf, consultada: 13 de marzo de 2021.

${ }_{9}^{9}$ Resolución de la Asamblea General de las Naciones Unidas, A/74/226, 25 de julio de 2019, https:// undocs.org/pdf?symbol=es/A/74/226, consultada: 8 de abril de 2021 .

${ }^{10}$ Linos, Katerina; Pegram, Tom, Interrogating form and function: designing effective national human rights institutions, The Danish Institute for Human Rights, Copenhague, 2015, p. 5.
} 
y propender hacia el efectivo cumplimiento de las normas y estándares de derechos humanos. Las comisiones tienen como misión principal asesorar a los organismos del Estado en la elaboración de una política de derechos humanos, generar y difundir conocimiento para crear conciencia sobre materias de derechos humanos $\mathrm{y}$, en algunos casos, recibir denuncias individuales de violaciones a los derechos humanos, investigarlas y cumplir un rol no-jurisdiccional de conciliación o arbitraje. ${ }^{11}$ El segundo modelo corresponde al del Ombudsman o, en su versión Iberoamericana, el "Defensor del Pueblo" (DP). De origen sueco, el modelo del Ombudsman clásico se basa en un órgano de carácter unipersonal, enfocado en el conocimiento de denuncias individuales, para lo cual posee robustas facultades de investigación. ${ }^{12}$ Se trata de un organismo que tiene un mandato amplio y general orientado a revelar y abordar los casos de "mala administración" y trato injusto a los ciudadanos por parte de las autoridades, erigiéndose en un vigilante de la administración pública (watchdog). ${ }^{13}$ Cuando incluye un mandato de promoción y protección de derechos humanos, el Ombusdman se constituye en una de las INDHs reconocidas por el DIDH. ${ }^{14}$ Este modelo híbrido - que actualmente ha sido adoptado por la mayoría de las INDHs del mundo ${ }^{15}$-, ha sido ampliamente adoptado en Latinoamérica bajo el nombre de DP o "Procurador de Derechos Humanos", entre otras denominaciones afines. ${ }^{16}$ En el marco de los procesos de democratización en América Latina hacia fines del siglo veinte, este modelo fue impulsado por los gobiernos con el objetivo de dotarse de un marco jurídico adecuado a las democracias que comenzaban a (re)construirse, introduciendo mecanismos eficaces de protección de los derechos humanos. ${ }^{17}$

${ }^{11}$ Pinheiro, Paulo; Baluarte, David, "National strategies - Human Rights Commissions, Ombudsman and National Action Plans", Human Development Reports, 2000, p. 2.

${ }^{12}$ Linos, Katerina; Pegram, Tom, "What works in human rights institutions?", American Journal of International Law, 2017, Vol. 111, No 3, p. 5.

${ }^{13}$ De Witte, Bruno, "National Equality Institutions and the domestication of EU Non-Discrimination Law", Maastricht Journal of European and Comparative Law, 2011, Vol. 18, No 1-2, p. 163.

${ }^{14}$ Mertus, Julie, The United Nations and Human Rights: A guide for a new era, Routledge, Nueva York, 2009, p. 28.

${ }^{15}$ ReIf, Linda, The ombudsman, Good Governance and the International Human Rights System, Springer, Leiden, 2004, p. 393.

${ }^{16}$ Cardenas, Sonia, Chains of justice, University of Pennsylvania Press, Philadelphia, 2014, p. 9.

${ }^{17}$ Aylwin, José, Ombudsman y derechos indígenas en América Latina: estudio comparativo sobre el 
A nivel regional, el primer DP se estableció en Guatemala en 1985, expandiéndose hacia varios países en la región, con excepción de Chile y Uruguay. ${ }^{18}$ Considerando los desafíos que existen en la región en materia de protección de derechos, el DP tiene un rol más visible que sus pares europeos. ${ }^{19}$ En nuestro continente, los problemas parecen ser más graves: detenciones ilegales, violencia policial, casos de tortura y, en general, otras violaciones graves a los derechos humanos que exigen fortalecer la institucionalidad pertinente. De ahí que su rol de protección y promoción de los derechos humanos sea preponderante frente a la mera defensa de un derecho a la "buena administración". En este sentido, además de la función de defensa judicial o administrativa de los derechos de los administrados frente a los poderes del Estado, el Defensor del Pueblo tiene atribuciones similares a las que tiene el modelo de "Comisión de Derechos Humanos". ${ }^{20}$ Por otra parte, el DP se erige como una alternativa a modelos de implementación de derechos humanos basados en el litigio, toda vez que esta institución supone la posibilidad de encauzar los reclamos de los ciudadanos frente a la administración de manera gratuita y desformalizada, ahí donde las vías jurisdiccionales son de difícil acceso, lentas y costosas. ${ }^{21}$ En términos generales, el DP latinoamericano no posee carácter jurisdiccional, ya que no tiene capacidad para interpretar el derecho con un carácter general y vinculante. En algunos casos, sin embargo, el DP podrá dictar medidas de cumplimiento obligatorias en materia de protección de derechos o intervenir en procesos jurisdiccionales. ${ }^{22}$

marco normativo e institucional, Instituto Interamericano de Derechos Humanos, San José, 2006, p. 56.

${ }^{18}$ Constenla, Carlos, Teoría y Práctica del Defensor del Pueblo, Editorial Reus, Madrid, 2010, p. 235. En Uruguay, si bien la "Institución Nacional de Derechos Humanos y Defensoría del Pueblo" es parte del GANHRI y de la Federación Iberoamericana del Ombudsman, su estructura orgánica es la de un órgano colegiado.

19 Valladares, Leo, "El Ombudsman como canal de acceso a la justicia", Revista Instituto Interamericano de Derechos Humanos, 2001, Vol. 32-33, p. 36.

${ }^{20}$ Aylwin, cit. (n. 17), p. 62.

${ }^{21}$ Dodd, Lynda, "Reassessing the Rights Revolution”, en: Dodd, L (Ed.), The rights revolution revisited: Institutional perspectives on the private enforcement of civil rights in the US, Cambridge University Press, Cambridge, 2018, p. 19.

${ }^{22}$ Constitución de Ecuador, artículo 215 № 2. 
3. ¿Importa el diseño de las instituciones nacionales de derechos humanos?

Antes de abordar las preguntas constitucionales relevantes, es importante detenerse en cuestiones generales sobre la importancia del diseño institucional de las INDHs. Diversos autores han desarrollado estudios empíricos que, aun cuando no impliquen probar una relación de causalidad entre diseño y rendimiento institucional, si permiten inferir el impacto específico que determinados diseños provocaron en el comportamiento y el resultado de distintas INDHs a nivel comparado. ${ }^{23}$ Otros autores estiman que la efectividad de las INDHs no depende del diseño especifico, sino que de la naturaleza de los derechos que se pretenden tutelar. Así, por ejemplo, y más allá del diseño institucional, la sola existencia de las INDHs incrementaría la probabilidad de prevenir, reparar y detectar los abusos contra la integridad física y de generar efectos uniformes en cuanto a derechos civiles y políticos. ${ }^{24}$ En términos generales, como señala Carver, medir el rendimiento institucional es un desafío de grandes proporciones, "sobre todo debido a los problemas para identificar el progreso en el respeto de los derechos humanos, y mucho más para entender el impacto de intervenciones particulares". ${ }^{25}$ Igualmente, al momento de establecer conexiones entre el diseño formal de una institución y su eficacia, siempre será posible cuestionar si dicho desempeño estuvo determinado por los actores directamente involucrados antes que por su configuración institucional. ${ }^{26}$ Así, aún cuando se considere que el diseño institucional es relevante para la efectividad de la INDH, debe tenerse presente la existencia de otros factores que podrían incidir de manera sustantiva en esta.

Según Livingstone y MurRaY, se pueden reconocer tres categorías de criterios que inciden en la efectividad las INDHs, a saber: capacidad, desempeño y legitimidad. ${ }^{27}$ Solo el primer criterio está referido a elementos

\footnotetext{
${ }^{23}$ Linos y Pegram, cit. (n. 10), pp. 34-37.

${ }^{24}$ Cole, Wade; Ramirez, Francisco "Conditional Decoupling: Assessing the Impact of National Human Rights Institutions, 1981 to 2004”, American Sociological Review, 2013, Vol. 78, № 4, p. 703.

${ }^{25}$ CARver, Richard, "One NHRI or Many? How Many Institutions Does It Take to Protect Human Rights? - Lessons from the European Experience", Journal of Human Rights Practice, 2011, Vol 3, $\mathrm{N}^{\circ} 1$, p. 8.

${ }^{26}$ BARKow, Rachel, "Insulating Agencies: Avoiding Capture Trough Institutional Design”, Texas Law Review, 2010, Vol. 89, № 1, p. 61.

${ }^{27}$ Livingstone y Murray, cit. (n. 2), pp. 141-145.
} 
de diseño institucional, mientras que el segundo y el tercero dicen relación con la manera en que la institución ejerce sus atribuciones y los efectos que genera en la ciudadanía o en otros órganos del Estado. Richard CARVER añade y explica otros criterios, que pueden ser sistematizados del siguiente modo: ${ }^{28}$ i) accesibilidad y cultura organizativa abierta: la institución se percibe como accesible, no burocrática y colaborativa; ii) composición: los miembros de la institución tienen integridad, experiencia y capacidad de adaptarse a los cambios; iii) diversidad: los miembros y/o el personal de la institución son reflejo de grupos sociales clave, con equilibrio de género; iv) relaciones de trabajo eficaces con la sociedad civil; v) mandato y jurisdicción amplias, respecto de varios temas y organismos estatales (así como de actores no estatales en algunos casos); vi) poder de supervisión: supervisar la respuesta de las autoridades a las recomendaciones que se emitan; vii) enfoque sistémico: las instituciones eficaces identifican las cuestiones prioritarias de derechos humanos, en lugar de dejarse llevar por las quejas del público o las peticiones del gobierno; viii) presupuesto público adecuado; xi) legitimidad pública: se deriva en parte del estatus formal de la institución, pero se asocia principalmente a la percepción de que es independiente y está preparada para defender los derechos humanos de forma imparcial.

En este contexto, y conscientes del desajuste que puede existir entre diseño y mayor protección de los derechos humanos, advertimos que el estudio del diseño institucional de una INDH debe asentarse principalmente en la realidad de Chile y en la praxis de sus instituciones. Además de lo anterior, estimamos útil pensar el fenómeno del diseño desde la perspectiva de la "fortaleza institucional" propuesta por Murillo, LevistKy y BrinKs. Para estos autores, una institución es fuerte no tanto por sus atribuciones "en el papel", sino porque generan "un resultado sustancialmente diferente del que se advertiría en su ausencia, y porque continúa produciendo ese resultado incluso frente a presiones para cambiarlo o evitarlo por completo". ${ }^{29}$ Se trata de un estándar exigente, ciertamente, pero que puede servir como un ideal regulativo que permita orientar el ejercicio de la imaginación institucional requerida en un proceso constituyente. Si bien es cierto que este tipo de

\footnotetext{
${ }^{28}$ CARVer, cit. (n. 25), p. 8.

${ }^{29}$ Murillo, Victoria; Levistky, Steven; Brinks, Daniel, La Ley y la trampa en América Latina: por qué optar por el debilitamiento institucional puede ser una estrategia política, Siglo veintiuno, México D.F., 2021, p. 107.
} 
instituciones no son una panacea, y que su mera existencia no es garantía de eficacia, lo cierto es que, aún cuando funcionen de modo imperfecto, es posible pensar que sin ellas estaríamos en una situación peor en materia de protección a los derechos humanos.

\section{LA DIMENSIÓN CONSTITUCIONAL DE LAS INSTITUCIONES NA- CIONALES DE DERECHOS HUMANOS}

\section{Las INDHs como instituciones que protegen la democracia constitucional}

En esta sección, cabe retomar algunas de las preguntas formuladas al comienzo de este trabajo. ¿Es la institucionalidad de derechos humanos un tema de relevancia constitucional o que concierne a un debate constitucional? ¿Es necesario garantizar la autonomía constitucional de las INDHs? Si las respuestas a estas preguntas son afirmativas, ¿de qué forma la nueva Constitución chilena puede abordar el diseño institucional de una INDH?

Incorporar ciertas instituciones, cláusulas o disposiciones en un texto constitucional puede obedecer a diversas motivaciones, que tienen como trasfondo diferentes formas de comprender la función de una constitución. Dependiendo de cómo definamos el objeto y función de una constitución, estas motivaciones pueden obedecer, entre otras, a la finalidad de limitar el poder político, de garantizar que aquellos actores u órganos que tienen poder de desestabilizar el orden constitucional puedan hacerlo o de lograr que los fines constitucionales se desarrollen eficazmente. ${ }^{30}$ Más allá de las diferentes funciones de una constitución, si seguimos el análisis de Carl ScHMITT sobre los diferentes conceptos de constitución, estas motivaciones se complejizan aun más. ${ }^{31}$ En efecto, como critica Schmitt, las constituciones han pasado de concebirse como formas de garantizar la unidad concreta o ideal de un orden o sistema político a un conjunto de leyes constitucionales que se reconocen por características externas, por ejemplo, por haber cumplido con los quórums de reforma constitucional respectivos. ${ }^{32}$ El concepto

\footnotetext{
${ }^{30}$ King, Jeff, "Constitutions as Mission Statements", en: Galligan, D.; Versteeg, M. (Eds.), Social and political foundations of constitutions, Cambridge University Press, New York, 2013, pp. 73-102.

${ }^{31}$ Schmit, Carl, Teoría de la Constitución, Alianza, Madrid, 1982, pp. 29-58.

${ }^{32}$ Schmitt, cit. (n. 31), p. 37.
} 
absoluto de constitución, que garantiza la unidad política concreta de un pueblo, o la unidad de un sistema de normas, se caracteriza usualmente por el adjetivo fundamental, de modo que los textos constitucionales garantizan esa unidad por contener "decisiones fundamentales", ya sean instituciones, órganos o derechos fundamentales. ${ }^{33}$ Por el contrario, el concepto relativo de constitución, caracterizado usualmente a través de los requisitos formales a partir de los cuales reconocemos y distinguimos un texto constitucional de otros cuerpos normativos, supone alejarse de lo que realmente importa: pasa a ser constitucional todo aquello que pueda identificarse por características o por el cumplimiento de requisitos formales.

Usualmente, la incorporación de instituciones u órganos del Estado en los textos constitucionales se enmarca en la doctrina clásica de la separación de poderes, en virtud de la cual la mejor manera de garantizar la legitimidad o estabilidad del orden político, o la vigencia de los derechos fundamentales, era separando distintas funciones de gobierno en distintos órganos. Así, las funciones de crear las normas, implementarlas, y de resolver los desacuerdos que se generen sobre su significado y aplicación, corresponden a cada una de las ramas del poder estatal. Con el desarrollo incipiente de la burocracia administrativa moderna hacia fines del siglo XIX, se comienzan a concentrar diversas funciones en el poder ejecutivo. ${ }^{34} \mathrm{El}$ desarrollo de servicios públicos que, además de potestades de ejecución de normas, comenzaron a concentrar potestades normativas y de resolución de conflictos acerca de la aplicación de normas, comenzó a cuestionar la idea clásica de separación de poderes. Más allá de la concentración funcional, fue la inclusión de nuevas entidades u órganos en los textos constitucionales lo que generó una verdadera revolución en la idea de la separación de poderes. Si la constitución está en la cúspide del ordenamiento jurídico, argumentó Kelsen, es porque cumple funciones fundamentales que deben ser protegidas y aseguradas. Sin embargo, esa función no debería estar encomendada a alguno de los poderes clásicos, sino a un cuarto órgano jurisdiccional, ubicado más allá del poder judicial ordinario, y encargado de la protección de la democracia

\footnotetext{
${ }^{33}$ Schmitt, cit. (n. 31), pp. 100-101.

${ }^{34}$ Mc Lean, Janet; Tushnet, Mark, "Administrative bureaucracy", en: Tushnet, M.; Fleiner, T.: SAunders, C. (Eds.), Routledge handbook of constitutional law, Routledge, Londres y Nueva York, 2013.
} 
constitucional. ${ }^{35}$

De acuerdo con Mark TushnET, si la función de proteger la democracia constitucional es una de tipo fundamental, de carácter constitucional por derecho propio, entonces podemos sugerir una serie de instituciones que pueden ser abordadas por un texto constitucional, considerando los conflictos de intereses que pueden existir entre los poderes estatales tradicionales y la eventual erosión de los fines de una democracia constitucional. ${ }^{36}$ Así, por ejemplo, una agencia anti-corrupción investiga casos que pueden terminar minando la confianza en las instituciones públicas, y se les otorga autonomía constitucional en contextos en que mayorías políticas que controlan todos los poderes del Estado puedan tener incentivos para ocupar sus atribuciones e impedir el castigo de la corrupción. ${ }^{37}$ Por su parte, una comisión nacional de derechos humanos autónoma puede ser fundamental para intervenir cuando el resto de los poderes son incapaces de actuar a favor de los grupos desaventajados. Además, como señala el propio Tushnet, estas instituciones están llamadas a prevenir los conflictos de interés que se pueden suscitar intra o inter-temporalmente. ${ }^{38}$ Los primeros pueden tener lugar, por ejemplo, cuando una coalición política controla el poder ejecutivo, pero no el poder legislativo, para lo cual se genera un método de resolución de conflictos en torno a la interpretación de las potestades de cada uno. Los segundos tienen lugar cuando las decisiones de los poderes del Estado en la actualidad pueden generar un daño a la democracia constitucional en el futuro, cuestión que explica la existencia de bancos centrales autónomos con el poder de controlar la política monetaria y mantener la estabilidad de los precios para las generaciones futuras. Sin embargo, además de la independencia que requieren las instituciones que protegen la democracia constitucional, se requiere un balance con el control que debe existir sobre estas mismas instituciones. En efecto, los poderes de control y de protección de la democracia constitucional se pueden ejercer abusivamente. De ahí,

\footnotetext{
${ }^{35}$ Kelsen, Hans, "La garantía jurisdiccional de la Constitución”, Revista Iberoamericana de Derecho Procesal Constitucional, 2008, No 10.

${ }^{36}$ Tushnet, Mark, "Institutions Protecting Constitutional Democracy: Some conceptual and methodological preliminaries", University of Toronto Law Journal, 2020, Vol. 70, № 2, pp. 104-105.

${ }^{37}$ Courtney, Millina, "When Should We Put Anticorruption Agencies in the Constitution?", The Global Anticorruption Blog, 18 de Julio de 2016, https:/globalanticorruptionblog.com/2016/07/18/ when-should-we-put-anticorruption-agencies-in-the-constitution/, consulta: 23 de marzo de 2021.

${ }^{38}$ Tushnet, cit. (n. 36), pp. 98-99.
} 
por ejemplo, la importancia de establecer regímenes de compensación o de responsabilidad de estas instituciones, como causales de remoción de quienes ejercen cargos en ellas.

Abordar la dimensión constitucional de las INDHs no puede reducirse al reconocimiento de su autonomía en una cláusula o capítulo específico de un texto constitucional. En efecto, la dimensión constitucional de ciertas instituciones puede derivar de otras normas constitucionales que asignan una importancia crucial al desarrollo de ciertas funciones de una INDH. Si bien el reconocimiento constitucional de la autonomía de las INDHs usualmente va acompañado de una regulación de los mecanismos de nombramiento de sus directores o representados, de una descripción de las funciones y delimitación de sus ámbitos de competencia, además de algunos mecanismos de control, la dimensión constitucional de las INDHs no se reduce a la discusión sobre su autonomía. En efecto, una norma constitucional podría reconocer un determinado derecho y establecer una obligación de crear una normativa que contemple una institucionalidad para realizar o hacer realidad aquel derecho. Sin embargo, en lo que sigue, abordaremos la dimensión constitucional de las INDHs a partir de las razones que puedan ofrecerse para incorporar tales instituciones como parte relevante de un texto constitucional.

2. La autonomía constitucional de las instituciones nacionales de derechos humanos

Es importante profundizar en uno de los argumentos esgrimidos por Mark TushneT en torno a las razones para preferir que las instituciones destinadas a proteger la democracia constitucional se encuentren en la propia constitución y no meramente a nivel legislativo. Hasta ahora, los argumentos ofrecidos aquí aportan razones para entregar funciones de controly protección de la democracia constitucional a instituciones específicas, pero no para sostener que estas instituciones deben estar incluidas necesariamente en una constitución. En lo que sigue, nos referiremos a las razones que se pueden ofrecer, en el marco del derecho constitucional chileno, para ir agregando instituciones en un texto constitucional, garantizando su autonomía a través de una sección o capítulo especial.

El ejercicio de ofrecer razones para ello contrasta con la falta de debate que ha existido, en diversos momentos de la historia constitucional chilena, 
para justificar la incorporación de autonomías constitucionales. Una buena manera de entender esto es considerando la incorporación de la Contraloría General de la República (CGR) al texto constitucional de 1925 y la del Banco Central (BC) a la Constitución de 1980. Según PARDow, la incorporación e implementación de estas autonomías constitucionales fue gradual, ya que tanto el origen del diseño institucional del BC como de la CGR no estaban pensados para ser incluidos en los textos constitucionales respectivos. ${ }^{39}$ En el caso del $\mathrm{BC}$, su autonomía se reconoció, en primer lugar, en el artículo 47 de la Constitución de 1980, y fue discutida brevemente en las actas de la denominada Comisión Ortúzar, que destacó por la falta de profundidad que se dedicó a las implicancias y consecuencias de la autonomía constitucional del Banco Central, a excepción de algunas polémicas generadas por la pérdida total del gobierno de poderes en política cambiaria, y por la eventual imposición de una política económica determinada en el texto constitucional. ${ }^{40}$ A pesar del reconocimiento constitucional del BC en 1980, fue sólo a través de un Decreto Ley promulgado por la dictadura que el diseño institucional de esta institución logró implementarse, después de conocerse los resultados del plebiscito de 1988, y sin una discusión técnica abierta con expertos de diversos sectores. ${ }^{41}$ La falta de legitimidad política gatilló diversos comentarios, sobre todo por la oportunidad de la entrada en vigencia de la ley del BC, que otorgaba a la dictadura el poder de nombrar a los miembros de su Consejo, quienes asumirían sus funciones el 9 de diciembre de 1989, es decir, sólo cinco días antes de la fecha fijada para las elecciones presidenciales y parlamentarias de aquel año. ${ }^{42}$ En el caso de la CGR, que se incorporó a la Constitución de 1925 en el año 1943, las razones para su incorporación al texto constitucional obedecieron a la necesidad de reconocer que tal institución ya se encontraba desarrollando un rol de "importancia constitucional" que requería ser protegido constitucionalmente. Como señala JiMÉNEZ, las razones ofrecidas en aquel entonces se relacionan con

${ }^{39}$ PARDow, Diego, “¿Control o autonomía? El debate sobre agencias regulatorias independientes”, Revista de Derecho (Valdivia), 2018, Vol. 31, № 2, pp. 202-206.

${ }^{40}$ Actas de la Comisión Ortúzar, Sesión No 399, 12 de Julio de 1978, pp. 645-654, https://www.bcn. cl/lc/cpolitica/actas_oficiales-r, consulta: 14 de enero de 2021.

${ }^{41}$ Noticia: "Ley del Banco Central deberá ser modificada", El Mercurio, 18 de agosto de 1989.

${ }^{42}$ Bianchi, Andrés, "La independencia del Banco Central de Chile: los años iniciales", en: NAudon, A.; Álvarez, L. (Eds.), 25 años de autonomía del Banco Central de Chile, Banco Central, Santiago, 2016, p. 25. 
el contexto de una reforma constitucional que aumentaba las atribuciones en materia de regulación económica para el poder ejecutivo, y la necesidad de generar alguna salvaguarda en caso de abuso de esos poderes. ${ }^{43}$ En ninguno de las casos, las razones para incorporar estas instituciones al texto obedecían a algún tipo de criterio para distinguir las cuestiones que pudieren ser objeto de regulación legislativa o de regulación constitucional.

Una primera razón para incorporar instituciones a la constitución, como sugiere el propio Tushnet, es de carácter nominalista, en virtud de la cual las instituciones se incorporan en un texto constitucional porque tienen en común la función de proteger la democracia constitucional. ${ }^{44}$ En otras palabras, las instituciones autónomas incluidas en un texto constitucional, más allá de los tres poderes tradicionales, están ahí porque todas ellas están llamadas a proteger la democracia constitucional. Su reconocimiento constitucional implica, por sí sólo, un grado de autonomía que permita cumplir la función de proteger el orden constitucional. En el caso chileno, por ejemplo, el adjetivo "autónomo" se usa a propósito del Servicio Electoral, del Ministerio Público, del BC, del Consejo Nacional de Televisión, de las municipalidades y de la CGR, pero no a propósito del Tribunal Constitucional, más allá de que este último sea el principal órgano encargado de proteger la democracia constitucional. Del mismo modo, desde esta primera perspectiva, nos podemos preguntar qué es lo que justifica, por ejemplo, que el Ministerio Público tenga el carácter de un órgano constitucional autónomo si su principal función no es proteger, al menos directamente, la democracia constitucional. Si bien es cierto que toda autonomía constitucional puede justificarse, en mayor o menor medida, en el fin de proteger la democracia constitucional, ello puede predicarse también de las autonomías de carácter meramente legal.

Una segunda razón, que ha tenido gran recepción en el discurso público, es que las autonomías constitucionales, a diferencia de las meramente legales, se crean para garantizar la estabilidad e independencia de la institución con respecto del legislador, quien pierde la facultad de eliminar la institución, aunque no totalmente respecto de su regulación. Los órganos se incluyen en la Constitución, de este modo, para garantizar su reforma dificultada o

\footnotetext{
${ }^{43}$ JIMÉNEZ, Guillermo, "Nonjudicial administrative justice in Latin America; a case study of the Chilean comptroller-general", Tesis doctoral, University College of London, 2018, p. 110.

${ }^{44}$ Tushnet, cit. (n. 36), p. 104-105.
} 
supra-mayoritaria y así lograr un "compromiso intertemporal que limite las oscilaciones de la política contingente". ${ }^{45}$ En el caso chileno, debemos recordar, algunas de estas autonomías constitucionales fueron realizadas por el constituyente de 1980, lo que agrega una dimensión anti-democrática en este respecto, ya que surgirían de la desconfianza del constituyente autoritario ante la deliberación democrática y de la necesidad de ciertas minorías de "amarrar" una institucionalidad ante el advenimiento de una democracia mayoritaria. ${ }^{46}$ Para algunos comentaristas, en el contexto chileno, esta tercera razón ha generado un frenesí de instituciones demandando que se les conceda una autonomía de rango constitucional, con el objeto de intentar asegurar su estabilidad con respecto a los poderes políticos de turno, y de sustraer ciertas cuestiones fundamentales de la discusión de la política democrática. ${ }^{47}$ Sin embargo, además, las autonomías constitucionales suponen evitar los tipos de supervigilancia o tutela que existen sobre las instituciones autónomas que crea el poder legislativo o ejecutivo, y que de algún modo u otro se encuentran en algún lugar dentro de la escala jerárquica de la administración. Toda autonomía, dependiendo de su nivel jerárquico, supone una limitación de los poderes legislativo o ejecutivo, es decir, de sus capacidades para crear o implementar las políticas que les permitan afianzar su legitimidad democrática. ${ }^{48}$

Una tercera razón es de tipo simbólica. De acuerdo con esta, preferir la inclusión de una institución autónoma en la Constitución en vez de garantizarla a través de una ley obedece al sentido político que tiene un texto constitucional, que goza de una mayor legitimidad democrática, o que se entiende, idealmente, como el producto de una deliberación más amplia que la que se da en el seno del proceso político ordinario. ${ }^{49}$ En otras palabras, en la política constitucional, es el pueblo el que aparece, a diferencia de los momentos de política ordinaria, donde los asuntos son principalmente

\footnotetext{
${ }^{45}$ Pardow, cit. (n. 39), p.199.

${ }^{46}$ Atria, Fernando; Salgado, Constanza; Wilenmann, Javier, Democracia y neutralización: Origen, desarrollo y solución de la crisis constitucional, Lom Ediciones, Santiago, 2017, p. 52.

${ }^{47}$ Véanse las opiniones de diversos expertos en la Historia legislativa de la reforma constitucional que otorga autonomía constitucional al Servicio Electoral (Ley No 20.860).

${ }^{48}$ Pardow, cit. (n. 39), p.198.

${ }^{49}$ Ackerman, Bruce; Ronsenkrantz, Carlos, "Tres concepciones de la democracia constitucional”, en: Ackerman, B.; Rosenkrantz, C.; Bouzat, Gabriel (dirs.), Fundamentos y alcances del control judicial de constitucionalidad, Centro de Estudios Institucionales, Buenos Aires, 1991.
} 
objeto del debate parlamentario y de los expertos en políticas públicas. Si aplicamos estas ideas a la creación de autonomías constitucionales, se le podría dar un particular sentido simbólico a estas últimas.

Ahora bien, ¿qué pasa si aplicamos las razones ofrecidas con anterioridad a la eventual incorporación de una INDH en la nueva Constitución chilena? En torno a la primera razón, no parecen quedar dudas de la importancia que tienen la promoción y protección de los derechos humanos en la preservación de una democracia constitucional. Las INDHs son fundamentales para la implementación efectiva de los compromisos internacionales de derechos humanos que han adoptado los Estados ante la comunidad internacional, para lo cual suelen formar parte de una institucionalidad que pretenda salvar la brecha existente entre los estándares internacionales y su vigencia práctica. Como veremos más adelante, y dependiendo de las atribuciones concretas que puedan ejercer, las INDHs se caracterizan por su capacidad de promover una cultura de derechos humanos más allá del Estado y por la inclusión de mecanismos de protección que van más allá de los que pueden ofrecer las cortes, que en la mayoría de las jurisdicciones no siempre son fácilmente accesibles para la protección de los derechos humanos. ${ }^{50}$ En palabras de Tushnet, "hacia fines del siglo XX, quienes diseñan constituciones llegaron a entender que la función de proteger la democracia constitucional podía ser realizada por diversas instituciones, algunas de las cuales están mejor posicionadas que las cortes constitucionales para proteger componentes específicos de la democracia constitucional". ${ }^{51}$ En el mismo sentido, Bulmer ha señalado que este tipo de instituciones, cuando son establecidas de manera apropiada y gozan de recursos y la confianza necesaria, pueden "contribuir a mejorar la calidad de la gobernanza, fortalecer el Estado de Derecho, fomentar la transparencia y la rendición de cuentas, prevenir la corrupción y, en última instancia, reforzar tanto la calidad como la resiliencia de la democracia." 52

La segunda razón para crear autonomías de rango constitucional parece tener cierto sentido a propósito de INDHs, que en América Latina han sufrido diversos impactos por la falta de estabilidad e independencia

\footnotetext{
${ }^{50}$ De Witte, cit. (n. 13), p. 167.

${ }^{51}$ Tushnet, cit. (n. 36), p. 96.

52 Bulmer, Elliot, Instituciones reguladoras y de supervisión independientes (de la cuarta rama): Guía introductoria 19 para la Elaboración Constitucional, IDEA Internacional, Estocolmo, 2021, p. 23-25.
} 
y por la gran cantidad de ejemplos de intervención política. ${ }^{53}$ En efecto, en sistemas presidenciales fuertes que cuentan con respaldo parlamentario, $\mathrm{y}$ en regímenes en donde los sistemas de frenos y contrapesos parecen perder la efectividad sin un respaldo institucional, las INDHs que gozan de autonomía meramente legal pueden quedar a merced de cambios en las mayorías políticas de turno. De acuerdo con PEAGRAM, quien ha realizado diversos estudios empíricos sobre INDHs en América Latina, "la evidencia es, en general, consistente con la idea de que el soporte constitucional conduce a una mayor estabilidad institucional". ${ }^{54}$ Como dato adicional, se puede señalar que ninguna de las INDHs que han elevado su rango jerárquico a nivel constitucional han perdido esa autonomía conferida. A pesar de ello, y de un estudio del funcionamiento y de las crisis por las que han atravesado diversas INDHs en la región, es posible sostener que la autonomía constitucional no implica que estas instituciones estén libres de intervención de los poderes políticos, sobre todo cuando estos retienen poderes de nombramiento, de definición legislativa de atribuciones, de financiamiento o de control. ${ }^{55}$ Por otra parte, también es posible observar INDHs con autonomías meramente legislativas desarrollar funciones claves para la protección de los derechos humanos, siempre y cuando el contexto político pertinente permita la consolidación institucional necesaria para ello, como el caso costarricense.

Con respecto a la tercera razón, que obedece a una de tipo simbólico, la inclusión de INDHs en un texto constitucional obedece a una cuestión de legitimidad pública. Según un estudio comparado de CARVER, mientras más alta sea la jerarquía normativa que da sustento a la institución, mayor es la legitimidad pública, de modo que las INDHs incluidas en una constitución parecen tener un sentido de propiedad pública, pertenecientes a la nación toda, comparado con aquellas que tienen un fundamento administrativo o legal, en donde parecen ser la creación de una entidad estatal que puede

${ }^{53}$ Peagram, Thomas, "National human rights institutions in Latin America: Politics and institutionalization", en: Goodman, R.; Peagram T. (Eds.), Human Rights, State, Compliance, and Social Change: Assessing National Human Rights Institutions, Cambridge University Press, New York, 2012.

${ }^{54}$ Peagram, cit. (n. 53), p. 212.

${ }^{55}$ Ackerman, John, Organismos autónomos y democracia: el caso de México, Siglo Veintiuno, México D.F, 2007. 
obedecer a sus propios intereses. ${ }^{56}$ Ahora bien, ello dependerá del grado de participación, inclusión y consulta pública que haya existido en el proceso constituyente en cuestión, como ha sucedido en los casos de Ghana y Sudáfrica. ${ }^{57}$

Como hemos visto aquí, la autonomía de una determinada institución no dependería tanto de su inclusión o no en la Constitución, sino de las autoridades que tienen poderes de designación, del modo y formas en que se definan sus funciones y atribuciones, y de los mecanismos de control que se determinen sobre ella. Sea definida en una ley o en la propia Constitución, lo relevante es que los poderes políticos, a través de la creación de autonomías institucionales, delegan funciones y atribuciones por razones técnicas con el objeto de satisfacer de mejor manera los bienes públicos, en este caso especial, la promoción y protección de derechos humanos. En la práctica constitucional chilena, el preferir garantizar esa autonomía en la Constitución tiene como correlato una intención de quitarle poder deliberativo al legislador para configurar institucionalmente la entidad en cuestión, intención que parte de la base de una profunda desconfianza en la capacidad de la política para articular soluciones adecuadas a los desafíos pertinentes. Sin embargo, si una de las principales funciones de una constitución es distribuir poderes entre diversas reparticiones u órganos del Estado que cumplen funciones de tipo fundamental, parece importante preguntarse por la eventual incorporación de una INDH en un nuevo texto constitucional para Chile. De optarse por su inclusión en el texto constitucional, lo que importa es el modo en que la constitución asigne y distribuya competencias antes que el uso del adjetivo autónomo que pueda utilizarse en la descripción del órgano. La autonomía constitucional así entendida depende, ante todo, de la delimitación de los espacios para la actuación normativa y resolutiva de sus propios asuntos, y de los regímenes de responsabilidad política que puedan existir sobre esta institución: de este modo, la constitución puede garantizar la autonomía de una institución, fijar su función y atribuciones, pero además impedir que ciertas potestades discrecionales pueden entenderse como un impedimento para hacer efectivas responsabilidades por el ejercicio imprudente o

\footnotetext{
${ }^{56}$ CARVER, Richard, "Performance \& Legitimacy: National Human Rights Institutions", International Council on Human Rights Policy, Ginebra, 2000, p. 108.

${ }^{57}$ Carver, cit. (n. 56), p. 108.
} 
negligente en el desempeño de las funciones. ${ }^{58}$

En esta sección hemos mostrado cómo las INDHs se han convertido en instituciones de relevancia constitucional, hemos examinado las razones que justifican otorgarles a estos órganos autonomía constitucional, y hemos destacado cómo debe entenderse dicha autonomía. En lo que sigue, y asumiendo que existen cada vez más textos constitucionales que tienden a especificar y desarrollar las características de la autonomía de las INDHs, ${ }^{59}$ retomaremos con más detalle algunas cuestiones básicas de diseño institucional ya esbozadas, incorporando, además, la discusión que se ha librado al respecto a nivel nacional. Se trata de importantes debates que la Convención Constitucional deberá tener presente en una eventual discusión sobre el diseño institucional de las INDHs.

\section{DILEMAS DE DISEÑO INSTITUCIONAL}

\section{Estructura orgánica}

Como señalamos al inicio, las INDHs pueden adoptar la forma de órganos unipersonales o colegiados. ¿Existen razones para preferir un modelo por sobre otro? En principio, es posible señalar que la adopción de un modelo u otro responde, generalmente, a factores históricos, contingentes y de cultura política e institucional. Según Elliot BuLmer, la elección de uno u otro modelo está determinada por el costo y las capacidades institucionales en cada país, por la configuración de hipótesis de responsabilidad y de rendición de cuentas, por la vulnerabilidad a situaciones de corrupción, por el grado de inclusión/diversidad que una institución sea capaz de incorporar $\mathrm{y}$, finalmente, por un tamaño adecuado a la carga de trabajo. ${ }^{60}$ Estos criterios pueden orientar la toma de decisiones y permiten considerar la realidad local y los problemas específicos que ya existen al interior de la institucionalidad

${ }^{58}$ FerradA, Juan Carlos, "Autonomía como técnica de reparto de potestades públicas: El caso del Banco Central de Chile”, Revista Chilena de Derecho, 1998, Número Especial, p. 344.

${ }^{59}$ A nivel comparado, se observa una gran diversidad de cláusulas constitucionales, que van desde la mera referencia a la institución en alguna disposición transitoria (Constitución de Guayana), a una regulación detallada de la integración de las INDH, sus funciones, atribuciones y procedimientos pertinentes, y su régimen de responsabilidad constitucional (Constitución de México).

${ }^{60}$ Bulmer, cit. (n. 52), pp. 23-25. 
vigente.

Desde la perspectiva comparada, cabe destacar que las INDHs de carácter unipersonal son abundantes en el mundo. ${ }^{61}$ Como advierte FrAHM, gran parte de la influencia del ombudsman o del DP no deriva de los poderes formales, sino de la reputación, el prestigio o la competencia que posee quien dirige la institución. ${ }^{62}$ En última instancia, el liderazgo personal es crucial, ya que las estructuras institucionales carecerían de sentido si no contaran con actores que las ocupen y les den significado. De acuerdo con los estudios empíricos realizados por Sonia CÁRDENAS, el liderazgo de las INDHs es determinante en condiciones de crisis y/o cuando los recursos son escasos. ${ }^{63}$ Por el contrario, liderazgos débiles en instituciones unipersonales pueden impactar negativamente al sistema de protección de derechos humanos en su conjunto. Por ello, el establecimiento de mecanismos de control y causales de cesación en este tipo de instituciones cobra especial relevancia. Para aminorar los riesgos de dependencia de liderazgos personales, en algunos casos se han introducido elementos de "cooperación" o de diversificación de liderazgos. ${ }^{64}$ Por ejemplo, en Suecia -donde se originó la figura del ombudsman-se designan a cuatro incumbentes, cada uno de los cuales tiene un ámbito de competencia particular, aunque la institución sea dirigida por uno solo de ellos. ${ }^{65}$ En Nueva Zelanda se prevé la posibilidad de elegir a más de un ombudsman. Al igual que en Suecia, en otros países como Bélgica, Austria y Bosnia y Herzegovina se contempla la existencia de entre dos y cuatro incumbentes. ${ }^{66}$

En relación con el caso chileno, el establecimiento de un órgano unipersonal como el Ombudsman o el DP ha sido promovido desde el año 1985, año en que se fundó el Capítulo Chileno del Ombudsman, al interior del denominado "Grupo de los 24". ${ }^{67}$ Por otra parte, y con anterioridad a

\footnotetext{
${ }^{61}$ Frahm, Michael, Australasia and Pacific Ombudsman Institution, Springer, Vienna, 2013; KucKsoStadlmeYer, Gabriele (Ed.), European Ombudsman-Institutions: A comparative analysis regarding the multifaceted realisation of an idea, Springer, Vienna, 2008.

${ }^{62}$ Frahm, cit. (n. 61), p. 13.

${ }^{63}$ Cardenas, cit. (n. 16), p. 355.

${ }^{64}$ Kuckso-Stadlmeyer, cit. (n. 61), p. 11-12.

${ }^{65}$ Kuckso-Stadlmeyer, cit. (n. 61), p. 12.

${ }^{66}$ Kuckso-Stadlmeyer, cit. (n. 61), p. 467.

${ }^{67}$ Miros, Domingo Juan, "Un defensor del pueblo para Chile”, Perspectivas en política económica y gestión, 1999, Vol. 3, No 1, p. 231.
} 
la creación del INDH-CHI, se habían ingresado múltiples proyectos de ley con el fin de introducir, con rango constitucional o simplemente legal, la figura del DP o de una Defensoría de las Personas (u otros órganos con denominaciones similares). ${ }^{68}$ Se trata, sin embargo, de proyectos con fisionomías sumamente diversas. Algunas propuestas pusieron énfasis en la protección de los derechos humanos, mientras que otras se enfocaban en la defensa de los usuarios y ciudadanos frente a la administración, tomando un cariz distinto, más cercano al Ombudsman clásico. Las razones que se han ofrecido a favor de un órgano unipersonal radican en la necesidad otorgar unidad y consistencia de acción de la institución ante el resto de los poderes del Estado, y de generar un impulso preciso y efectivo ante problemas que ameritan una intervención rápida y eficaz. ${ }^{69}$ Esto no significa que, en ejercicio de la autonomía organizacional, no se pueda desconcentrar la institución, creando defensores adjuntos, regionales y/o una estructura de divisiones que le permita atender las diversas situaciones que surjan en el cumplimiento de sus funciones. ${ }^{70}$ En este escenario, la unipersonalidad no obsta a la existencia de una estructura organizacional que permita desconcentrar, diversificar y coordinar las diversas funciones que las INDHs están llamadas a cumplir.

Ahora bien, para decidir si acaso se debe mantener el actual modelo colegiado del INDH-CHI o si se debe transitar a una estructura unipersonal, debe tenerse a la vista el modo en que ha funcionado en su primera década de existencia, con especial consideración de la capacidad de reacción que tuvo frente a la reciente crisis de derechos humanos que tuvo lugar en Chile a partir de octubre de 2019. Sobre esto último, es preciso señalar que el INDH-CHI desplegó al máximo sus capacidades institucionales, constituyéndose como un actor particularmente relevante en la protección de derechos humanos. No obstante, el denominado "estallido" social exhibió ciertas deficiencias en la estructura colegiada del INDH-CHI. Como hemos señalado en otro trabajo, el diseño del Consejo del INDH-CHI observa al menos dos grandes problemas. ${ }^{71}$ En primer lugar, dos miembros del

\footnotetext{
${ }^{68}$ V. Mensaje No286-632 de 26 de marzo de 1991; Boletín 3429-07; Boletín 6232-07; Boletín 1309907; Boletín 2115-03.

${ }^{69}$ Nogueira, Humberto, "Un enfoque Constitucional", en Ministerio Secretaría General de la Presidencia (Eds.) El Defensor ciudadano que queremos. Proyecto de Reforma y Modernización del Estado, Gobierno de Chile, Santiago, 2001, p. 72-73.

${ }^{70}$ Nogueira, cit. (n. 69), p. 73.

${ }^{71}$ Aylwin, Vicente; Coddou, Alberto; Vial, Tomas, "El INDH y el estallido social”, en: Vargas, F.
} 
Consejo, el órgano político del INDH-CHI, son elegidos por el Presidente, con lo cual se atenta directamente en contra el principio de autonomía y de no representación gubernamental derivado de los Principios de Paris. En segundo lugar, el director del INDH-CHI es un consejero elegido por la mayoría absoluta de los miembros del Consejo. Esta característica de diseño puede volverse problemática en momentos de crisis, en el entendido de que los mecanismos de nombramiento de los consejeros incluyen la participación de diferentes órganos del Estado y actores de la sociedad civil con determinados intereses, que desarrollan prácticas de negociación política. Así, que el director sea a su vez un consejero de un órgano colegiado aquejado por problemas de "politización" puede afectar no solo la gestión ejecutiva sino también la legitimidad simbólica de la institución y su imagen como un órgano independiente sujeto al cumplimiento de un mandato legal. ¿Qué pasaría, por ejemplo, en aquellos casos en que el Director es un consejero nombrado por el Presidente? A los problemas de diseño, se suman ciertas prácticas que responden a una cultura política binominalizada que va "cuoteando" la asignación de cargos públicos sin someter a escrutinio los nombramientos, cuestionando la legitimidad técnica del INDH-CHI. ${ }^{72}$ Desde esta lógica, ciertos cargos pueden ser vulnerables al pago de favores políticos, la mantención de alianzas, o la cooptación de ciertas instituciones con finalidades partisanas. Estos problemas se hicieron patentes durante el "estallido social", en tanto que el Consejo del INDH-CHI apareció dividido en "bandos" en torno a ciertos asuntos sumamente controvertidos. El problema radica en que el actual diseño del órgano colegiado presupone la existencia de ciertos consensos, los que, una vez rotos, terminan por debilitar la capacidad operativa y la imagen de la institución. ${ }^{73}$

(Ed.), Informe Anual sobre Derechos Humanos en Chile, Ediciones UDP, Santiago, 2020, pp. 43-81. ${ }^{72}$ NAsh, Claudio, “A propósito del affaire Micco: ¿Llegó el momento de discutir a fondo la institucionalidad de derechos humanos en Chile?, 2020, https://www.ciperchile.cl/2020/05/09/aproposito-del-affaire-micco-llego-el-momento-de-discutir-a-fondo-la-institucionalidad-de-derechoshumanos-en-chile/, consulta: 13 de julio de 2021.

${ }^{73}$ Sobre el particular, una encuesta encargada por el INDH-CHI muestra el grave deterioro de la imagen de la institución frente a la ciudadanía: solo un 14\% estimó que la institución protegía los derechos humanos de todas las personas; ante a una vulneración de derechos, solo un $16 \%$ recurriría al INDH, mientras que el $26 \%$ de los encuestados acudiría a Carabineros de Chile, pese a los cuestionamientos que existen sobre esta última institución a propósito de violaciones a los derechos humanos en el contexto del "estallido social"; el 20\% de los encuestados dice no conocer el INDH-CHI, porcentaje que aumenta en estratos socioeconómicos más bajos (29\%). Instituto Nacional De Derechos Humanos, 
Sea cual sea el modelo o la estructura orgánica que se adopte, abordar estos problemas requiere urgentemente el establecimiento de mecanismos de designación de miembros que garanticen independencia política, la integridad y la objetividad, sin dar especial favor a partidos políticos, facciones, secciones de la sociedad o grupos de interés que excluyan voces alternativas. ${ }^{74}$ Esto es necesario "para fomentar la confianza en la institución $\mathrm{y}$, por consiguiente, garantizar que todos los actores respeten su decisiones". ${ }^{75}$ Al mismo tiempo, un correcto diseño institucional debe asegurar, por sobre todo, la capacidad de acción efectiva de una INDH, particularmente en momentos de crisis. Ello requiere, por cierto, mecanismos que permitan minimizar los riesgos de bloqueo, cooptación y paralización.

\section{Concentración o fragmentación de instituciones}

En relación con el número de órganos que debe contemplar una institucionalidad de derechos humanos y los ámbitos de competencia que deben cubrir, surge el siguiente dilema: crear instituciones distintas para la protección de diferentes derechos humanos o de diversos grupos vulnerables, o bien, concentrar las variadas funciones y ámbitos en una sola institución. La primera alternativa implica fragmentar la institucionalidad, creando diversos órganos dedicados a la protección y promoción de derechos humanos de ciertos grupos específicos. La segunda alternativa promueve un modelo concentrado, que opta por la creación de una sola institución con atribuciones concentradas o que utiliza las capacidades instaladas que ya han sido desarrolladas por instituciones preexistentes, ampliando el mandato de estas últimas. ${ }^{76}$ De este dilema surgen algunas interrogantes interesantes de explorar: ¿cuántas instituciones se necesitan para proteger los derechos humanos? ¿más instituciones equivale a una mayor y mejor protección? ¿están mejor resguardados los derechos de grupos específicos, especialmente vulnerables, con instituciones exclusivamente dedicadas

\footnotetext{
"Informe de Resultados: Encuesta Nacional de Derechos Humanos 2020", 2020, https://www.indh.cl/bb/ wp-content/uploads/2021/06/Encuesta-Nacional-de-DDHH-2020.pdf, consultada: 12 de julio de 2021.

${ }^{74}$ Bulmer, cit. (n. 52), p. 25.

${ }^{75}$ Bulmer, cit. (n. 52), p. 25.

${ }^{76}$ Coddou, Alberto, "La institucionalidad de derechos humanos en Chile", en: VARGAs, F. (Ed.), Informe Anual sobre Derechos Humanos en Chile, Ediciones UDP, Santiago, 2019, p. 540.
} 
a su protección? Según Richard CARVER, no existe un argumento a priori para adoptar una u otra solución en este sentido. ${ }^{77}$ En efecto, la elección tendrá que adoptarse en función del modelo que pueda asegurar la mejor protección, esto es, una protección efectiva y real de los derechos humanos de acuerdo con un análisis institucional comparado. ${ }^{78}$

En favor de la fragmentación se han esgrimido al menos tres grandes argumentos que se construyen a partir de las potenciales deficiencias de una institucionalidad única o concentrada. El primero de ellos dice relación con la especificidad de la protección, ya que una institucionalidad concentrada no podría abordar las necesidades particulares de los colectivos especialmente vulnerables, sobre todo en comparación a una institucionalidad fragmentada que tendría un punto de vista focal y especializado. En segundo lugar, se ha señalado que al interior de una institución concentrada existirían distintas prioridades y visiones, generando una constante competición por recursos y tensión respecto de cómo focalizarlos, o una jerarquía de categorías protegidas que compiten por atención institucional. ${ }^{79}$ En tercer lugar, se ha sostenido que podría ocurrir que una institución única tuviese un liderazgo débil, y con ello pudiere ocasionar consecuencias perniciosas para el sistema de protección de derechos humanos en su conjunto. ${ }^{80}$

A favor de la concentración, por su parte, se han esgrimido múltiples argumentos. En primer lugar, una institución regida por un marco legal unificado podrá aplicar de manera coherente e igualitaria los mismos estándares de protección de derechos humanos a todos los grupos e individuos, incluyendo estándares generales y específicos a cada uno de los grupos de especial protección. En segundo lugar, una institución concentrada que pueda cubrir diversas áreas de protección podría generar una "sinergia institucional" entre los distintos funcionarios, equipos o departamentos, de modo que se promueva el intercambio de conocimientos y, en definitiva, se contribuya a mejorar el rendimiento institucional. En tercer lugar, la aplicación de diversos estándares que pueden ser reconducidos al marco normativo que ofrece el DIDH, supone que la institución puede entregar un trato coherente y uniforme, con independencia de la materia de que se

\footnotetext{
${ }^{77}$ Carver, cit. (n. 25), pp. 7-8.

${ }^{78}$ Komesar, Neil, Imperfect Alternatives, University of Chicago Press, Chicago, 1994, p. 3-14.

${ }^{79}$ Bulmer, cit. (n. 52), p. 16.

${ }^{80}$ CARver, cit. (n. 25), pp. 9-10.
} 
trate. En cuarto lugar, desde una perspectiva económica, una sola institución podría ser mucho más costo-efectiva que una multiplicidad de instituciones. Finalmente, desde la perspectiva del ciudadano, una institución única podría facilitar a las personas la identificación de la institución a la que deben asistir en caso de requerir protección, así como del lugar físico al que dirigirse, otorgando una cobertura más igualitaria a todos los individuos. Esta identificación podría generar, a su vez, un mayor reconocimiento y apoyo público, con lo cual podría contribuirse a la legitimidad pública y simbólica de la institución.

A nivel comparado, este debate tuvo prominencia con ocasión de las obligaciones de los países miembros de la Unión Europa (UE) de crear organismos de igualdad que implementaran las directivas sobre igualdad y no discriminación. En primer lugar, las tempranas evaluaciones de la experiencia europea muestran que los órganos concentrados presentan ventajas en relación con la elaboración de estrategias transversales eficaces. ${ }^{81}$ Además, un órgano único puede proveer un enfoque coordinado, apto para prevenir la superposición de funciones y evitar la duplicidad en la asignación de recursos. ${ }^{82}$ La Comisión de la UE ha emitido diversas recomendaciones para que, en caso de múltiples órganos de igualdad, estos se puedan coordinar y cooperar $y$, por el contrario, para que una organización única no termine concentrando "sus energías de forma desproporcionada en algunas tareas en detrimento de otras". ${ }^{83}$ A pesar de que la evidencia existente apunta hacia fortalecer y consolidar instituciones únicas, es importante destacar que existen múltiples factores que pueden determinar el rendimiento institucional de una institución única, como el liderazgo personal de sus autoridades, el grado de autonomía que puede desplegar en la práctica o los mecanismos para protegerse de eventuales recortes presupuestarios o interferencias políticas. ${ }^{84}$ Las experiencias recientes en torno a este dilema regulatorio dan cuenta de procesos de evolución y adaptación institucional, ya que la arquitectura institucional en materia de derechos humanos no

\footnotetext{
${ }^{81}$ O'Cinneide, Colm, “A Single Equality Body: Lessons from Abroad”, Working Paper Series $\mathrm{N}^{\circ} 4$., Equal Opportunities Commission, London, 2002, p. 31.

${ }^{82}$ O'CinneIde, cit. (n. 81), p. 31.

${ }^{83}$ Recomendación de la Comisión de la Unión Europea (UE) N²018/951, 22 de junio de 2018, sobre normas relativas a los organismos para la igualdad.
}

${ }^{84}$ O'CINNEIDE, cit. (n. 81), p. 215. 
suele ser creada ex nihilo. En este escenario, resulta interesante observar cómo algunos países han ido transitando desde modelos fragmentados hacia modelos concentrados o híbridos. Así, el Reino Unido adoptó en el año 2006 un órgano único, denominado Commission for Equality and Human Rights, que reemplazó a tres comisiones especializadas que existían desde mediados del siglo veinte. ${ }^{85}$ Recientemente, Hungría adoptó un modelo híbrido en el que se establecieron cuatro órganos diferenciados de derechos humanos, pero que comparten un mismo edificio, tienen un presupuesto combinado, funcionarios comunes, y presentan acciones conjuntas ante los órganos jurisdiccionales. ${ }^{86}$ Como se observa, y más allá de las diversas configuraciones institucionales, existe una tendencia a consolidar la multiplicidad de organismos en una única institución de derechos humanos.

La institucionalidad chilena, por su parte, ha ido oscilando entre la fragmentación y la concentración. El primer fenómeno se manifestó con la dictación de la Ley 21.067 que creó la Defensoría de la Niñez (en adelante, DFN), momento a partir del cual empezaron a convivir múltiples órganos con autonomía y competencias distintas en materia de derechos humanos. ${ }^{87}$ El dilema concentración/fragmentación es especialmente importante en materia de protección de la niñez, por lo que cabe detenerse un momento en ello. Como antecedente, debe observarse que el Comité de Derechos del Niño ha venido exigiendo la creación de órganos autónomos de protección de la niñez en cumplimiento de la $\mathrm{CDN}^{88} \mathrm{y}$, para el caso chileno -antes de la creación de la DFN-, había reiterado su preocupación ante la ausencia de un defensor especializado. ${ }^{89}$ Como muestra la historia fidedigna de la

\footnotetext{
${ }^{85}$ Equality Act, 2006 (Reino Unido). En Australia y Suecia, por su parte, también se fusionaron diversos órganos u ombudsman especializados en una única institución o comisión.

${ }^{86}$ Kosztolanyi, Gusztav, “An Ombudsman to Protect Us”, Central Europe Review, 2001, Vol. 24, $\mathrm{N}^{\mathrm{o}} 3$.

${ }^{87}$ RavetLlat, Isaac, "El Defensor de los derechos de la niñez en Chile: Hacia un verdadero garante de su interés superior", Estudios Constitucionales, 2017, Vol. 15, No 1, pp. 225-306.

${ }^{88}$ Comité de los Derechos del Niño, Observación General N ${ }^{\circ}$ 2, doc. CRC/GC/2002/2, 15 de noviembre de 2002: http://docstore.ohchr.org/SelfServices/FilesHandler.ashx?enc=6QkG1d\%2FPPRiCAqhKb7 yhsiQq18gX5Zxh0cQqSRzx6ZcNR3YdFwaRoLFkDFvNRIVoZv3aKcWqVarwlCH6wwd4LR5MI72 oklbmnVFtku3\%2B01xRgfOF\%2BSAWIf3asQH\%2FxDOW, consulta: 16 de diciembre de 2021.

${ }^{89}$ Comité de los Derechos del Niño, Observaciones finales sobre los informes periódicos cuarto y quinto combinados de Chile, doc. $\mathrm{CRC} / \mathrm{C} / \mathrm{CHL} / \mathrm{CO} / 4-5,30$ de octubre de 2015: https://tbinternet. ohchr.org/_layouts/15/treatybodyexternal/Download.aspx?symbolno $=\mathrm{CRC} / \mathrm{C} / \mathrm{CHL} / \mathrm{CO} / 4-5 \& \mathrm{Lang}=\mathrm{Sp}$, consulta: 16 de diciembre de 2021.
} 
Ley 21.067, el dilema también apareció en la discusión legislativa donde se propuso en la Cámara acoplar la figura del Defensor al INDH, sin embargo, esta posición fue minoritaria. En favor de ella, el INDH expresó que la fragmentación de los órganos podría atentar contra su eficacia, y que la protección de NNA requería una institución suficientemente fuerte para cumplir su mandato de protección, fuerza que -expresó- ya se encontraba instalada en el INDH. ${ }^{90}$ En contra de esta posición, LOVERA ha dicho que la fragmentación, en general, y especialmente en el caso de los NNA no es un problema, más bien, por el contrario, es la alternativa que debe preferirse para atender la propia especificidad social de la promoción y protección de los derechos de NNA. ${ }^{91}$ Igual posición ha adoptado la Defensora de la Niñez, Patricia MuÑoz, en el marco de la discusión constituyente. En su exposición ante la Comisión de Sistemas de Justicia manifestó la necesidad de constitucionalizar la DFN, reforzando la idea de que la protección de NNA requiere de un organismo especializado y autónomo que asuma como el órgano rector del sistema de garantías de la niñez y adolescencia, y que pueda controlar el cumplimiento de las obligaciones de los distintos órganos con competencia en la materia. Arguye que existe una grave crisis de violación de los derechos humanos de la niñez y la adolescencia en Chile, cuestión que agudiza la necesidad de que la DFN mantenga su autonomía y no se subsuma en un órgano que "diluya" los derechos de NNA. Asimismo, agrega que cuando la defensa de los NNA queda entregada a un ombudsman general, en promedio, solo un $3 \%$ del presupuesto se destina a materias relacionadas con este grupo de especial protección. ${ }^{92}$

Por otra parte, cabe destacar que la concentración en materia de defensa deNNAno es nada extraña. Como dacuenta RAVETLLAT, el modeloconcentrado -o integrado como prefiere este autor- donde el Defensor de los Derechos

\footnotetext{
${ }^{90}$ Véase la Historia de la Ley N²1.067, en especial, intervenciones de Bransilav Marelic, Juan Cristóbal González Sepúlveda y Christian Finsterbusch en representación del INDH. BiBlioteca Del Congreso Nacional, "Historia de la Ley No 21.067: Crea la Defensoría de los Derechos de la Niñez", 2018, https://www.bcn.cl/historiadelaley/fileadmin/file_ley/7484/HLD_7484_37a6259cc0c1dae299a78664 89dff0bd.pdf .

${ }^{91}$ Lovera, Domingo "Institucionalidad de Derechos Humanos en Chile", en: NAVIA, C.; De la MazA, A. (Eds.), Seminario Internacional: "Institucionalidad de Derechos Humanos: Desafios para su creación e implementación”, INDH, Centro de Derechos Humanos UDP, Santiago, 2016, pp. 29-33.

${ }_{92}$ Véase la exposición de Patricia Muñoz el día 11 de noviembre de 2021, en la Comisión sobre Sistemas de Justicia, Órganos Autónomos de Control y Reforma Constitucional de la Convención Constitucional.
} 
de la Niñez se encuentra adscrito a una institución "más genérica", existe en varios países como Canadá, Hungría, Portugal, Sudáfrica y la gran mayoría de países latinoamericanos. ${ }^{93}$ Por la contra, el modelo de fragmentación es común en los países escandinavos, mientras que, en la región, solo ha sido adoptado a nivel nacional por Chile y Argentina. Finalmente, cabe decir que a pesar de las dificultades que supuso la instalación de la DFN, este órgano pudo constituirse como una institución de derechos humanos fundamental para la protección de NNA. ${ }^{94}$ Sin embargo, aún existen múltiples desafíos ${ }^{95} \mathrm{y}$ dificultades, entre ellas, las limitaciones presupuestarias y de dotación dadas por un sistema de financiamiento deficiente que favorece la vulneración de los derechos humanos de los NNA. ${ }^{96}$

En sentido inverso, la creación del Mecanismo Nacional de Prevención de Tortura (MNPT) favoreció la concentración de la institucionalidad, toda vez que la Ley 21.154 ubicó al MNPT en la estructura orgánica del INDH$\mathrm{CHI}$, con lo cual se aprovecharon las capacidades institucionales previamente instaladas. Este modelo, adoptado en diversos países de la región, implica la creación de un MNPT que, aunque formalmente adscrito a las INDHs, debe tener la independencia necesaria según lo prescrito en el Protocolo Facultativo de la Convención contra la Tortura. Esta concentración de la institucionalidad de derechos humanos tiene como ventaja la posibilidad de aprovechar las capacidades instaladas, facilitando la generación de diálogo con autoridades y organizaciones internacionales, así como la presencia y expansión del MNTP hacia las regiones donde el INDH-CHI tiene instaladas sus sedes. ${ }^{97}$

Como se observa, el proceso constituyente en curso abre un espacio para discutir sobre el futuro diseño de las instituciones de derechos humanos

\footnotetext{
${ }^{93}$ RavetLlat, cit. (n. 87), pp. 279-280.

${ }^{94}$ Cfr. Miranda, Fabiola; Andrade, Carlos, "Entrevista: Patricia Muñoz, Defensora de la Niñez", Revista del Departamento de Trabajo Social de la Universidad Alberto Hurtado, 2020, Vol. 10, № 1, p. 119-133. En esta entrevista, Patricia Muñoz refiere los desafíos de levantar una institución desde cero. Al respecto señala: "la creación de una institución por la vía de la ley no asegura el soporte orgánico o institucional para poder instalar una institucionalidad".

${ }^{95}$ Véase: Defensoría de LA NiÑEz (eds.), "Informe Anual 2021: Derechos humanos de niños, niñas y adolescentes en Chile”, Defensoría de los derechos de la Niñez, Santiago, 2021, pp. 143-149.

96 Valenzuela, Ester; Correa, Paula "Derechos humanos de niños, niñas y adolescentes. Infancia primero: lo prometido es deuda", en: VARGAS, F. (Ed.), Informe Anual sobre Derechos Humanos en Chile 2019, Ediciones UDP, Santiago, 2019, p. 271.

${ }^{97}$ Coddou, cit. (n. 76), p. 540.
} 
y sobre la adopción de un modelo concentrado o fragmentado, existiendo buenas razones para argumentar en favor de un diseño u otro. Una eventual concentración podría lograrse ampliando las facultades del INDH-CHI, y concentrando las competencias pertinentes en este órgano, o bien, por la vía de crear un órgano unipersonal que concentre las funciones de promoción y protección de derechos humanos. Es importante resaltar que la concentración institucional que hemos descrito no obsta a la creación de departamentos o divisiones especializados en materia de derechos humanos al interior de los órganos de la administración del Estado, que pueden estar coordinados por una división ministerial o por una obligación intersectorial de coordinación. En otras palabras, una institucionalidad de derechos humanos de carácter independiente se podría beneficiar de una relativa coordinación $o$ concentración de funciones en los órganos de la Administración, con quienes las INDHs suelen estar en constante comunicación y retroalimentación. La magnitud del desafío amerita, al menos, debatir estos temas en el marco de un proceso constituyente que abre posibilidades de imaginación institucional.

\section{Atribuciones}

En esta subsección se expondrán algunas de las atribuciones que tienen las INDHs a nivel comparado, poniendo énfasis en la regulación constitucional. Más allá de las atribuciones contempladas en los "Principios de París", centradas básicamente en acciones de promoción de derechos a través de recomendaciones sobre las políticas públicas pertinentes, la actual discusión se enfoca en la posibilidad de que las INDHs dispongan de atribuciones decisorias en caso de denuncias individuales o colectivas. En contextos donde existe un acceso restringido a la justicia, que dificultan la posibilidad de garantizar una tutela judicial efectiva, sobre todo para los grupos más desaventajados, las INDHs con atribuciones de recibir y resolver denuncias individuales o colectivas se erigen en mecanismos de justicia administrativa para la protección de derechos humanos. Ello, evidentemente, debe ser considerado a través de un análisis institucional comparado, que permita sopesar empíricamente las configuraciones institucionales que mejor se adapten al cumplimiento de las funciones de protección y promoción de derechos humanos. ${ }^{98}$ Diversos estudios han

${ }^{98}$ Komesar, cit. (n. 78), p. 3-15. 
destacado las ventajas institucionales que tendría generar mecanismos de justicia administrativa de derechos humanos, considerando la capacidad de las INDHs de recolectar y producir evidencia que permita probar violaciones de derechos humanos, ya sea en instancias de justicia administrativa o en procesos jurisdiccionales que puedan gatillar o intervenir. ${ }^{99}$ Más aun, considerando a las INDHs que adoptan el modelo ombudsman, esta importante función constitucional se refuerza por la estrecha vinculación con el reconocimiento del derecho a la "buena administración". ${ }^{100}$

En América Latina, numerosos textos constitucionales reconocen la figura del Ombudsman o DP. Algunas constituciones se limitan a ordenar su creación y regulación en una ley especial, mientras que otras constituciones enumeran y desarrollan sus atribuciones con diferentes grados de detalle. Esto último ocurre con las constituciones de Bolivia (artículo 222), Guatemala (artículo 275), Ecuador (artículo 215), Paraguay (artículo 279) y Venezuela (artículo 281). Si bien la regulación puede variar de una constitución a otra, existen elementos comunes que permiten justificar una suerte de modelo latinoamericano de INDHs incorporadas en textos constitucionales. En primer lugar, los textos constitucionales entregan un doble mandato de protección de los derechos humanos y de control de la administración. En segundo lugar, las constituciones de la región dotan al DP de amplísimas facultades de investigación. ${ }^{101}$ En tercer lugar, se les reconoce con mayor o menor amplitud una legitimación activa para interponer una serie de acciones judiciales, administrativas, constitucionales y, excepcionalmente, de carácter internacional. ${ }^{102}$ En otras palabras, más allá de la atribución de las INDHs de resolver por sí mismas las denuncias, ya sea en instancias de justicia administrativa o a través de mecanismos cuasi-judiciales, es de vital importancia que la vía judicial siempre esté disponible cuando las circunstancias así lo ameriten, sobre todo considerando la necesidad de resguardar los derechos de aquellos que no cuentan con acceso a otras vías institucionales. Es precisamente esta legitimación procesal la que permite

\footnotetext{
${ }_{99}$ Buck, Trevor; BiRкham, Richard; Thompson, Brian, The Ombudsman enterprise and Administrative Justice, Ashgate, London, 2011.

${ }^{100}$ Buck, Birkham y Thompson, cit. (n. 99), p. 224.

${ }^{101}$ Aylwin, José cit. (n. 17), p. 74-75.

${ }^{102}$ Aguilar, Gonzalo; Steward, Rebecca, "El Defensor del Pueblo Latinoamericano como institución independiente de promoción y protección de los derechos humanos", Revista de Derecho Universidad Católica del Norte, 2008, año 15, No 2, p. 36.
} 
que el DP pueda asegurar el acceso a la justicia.

En el caso de algunas defensorías de la región, sus atribuciones se encuentran desarrolladas en leyes especiales, lo que ha permitido generar cierta innovación institucional. En este contexto, es importante destacar ciertas facultades en relación con los derechos de la naturaleza y de los pueblos originarios. En el caso de Ecuador, la ley respectiva define a la DP como la "Institución Nacional de Protección y Promoción de los Derechos Humanos y la Naturaleza". ${ }^{103}$ El artículo 8 del mismo cuerpo legal establece la competencia de esta institución para "intervenir como parte en asuntos relacionados a la protección del medio ambiente y del patrimonio cultural resguardando el interés de la colectividad", al mismo tiempo que puede "promover la capacitación de difusión y asesoramiento en el campo de los derechos humanos, ambientales y de patrimonio cultural". Por otra parte, esta ley encarga a la Defensoría del Pueblo implementar el Mecanismo Nacional de Prevención, Precaución, Protección, Promoción y Restauración de los Derechos de la Naturaleza (PACHAMAMA), con énfasis en la biodiversidad de las regiones amazónica, insular y fronteriza. ${ }^{104}$ Desde la perspectiva práctica, la Defensoría del Pueblo ha recibido causas presentadas por parte de comunidades, colectivos o personas en relación con los derechos del medioambiente, así como casos en que se encontraba en riesgo la naturaleza o sus ciclos vitales. ${ }^{105}$

Por otra parte, debe considerarse que los Defensores del Pueblo pueden configurarse como órganos eficaces para la promoción y protección ya no solo de derechos civiles y políticos, sino también de los derechos económicos, sociales y culturales (DESC). ${ }^{106}$ En efecto, las capacidades institucionales de las INDHs para recolectar y analizar información desagregada permite ilustrar el modo en que las desigualdades socio-económicas afectan al goce y ejercicio de derechos civiles y políticos, constituyendo una poderosa herramienta en contextos donde no se garantiza la justiciabilidad

\footnotetext{
${ }^{103}$ Ley Orgánica de la Defensoría del Pueblo (Ecuador).

${ }^{104}$ Artículo 22 de la Ley Orgánica de la Defensoría del Pueblo (Ecuador).

${ }^{105}$ Naranjo, Mónica "Derechos de la naturaleza y la gestión de la defensoría del pueblo de ecuador", Tesis de máster en derecho, FLACSO, Quito, 2016.

${ }^{106}$ Moure, Ana María, El Ombudsman: un estudio de derecho comparado con especial referencia a Chile, Dykinson, Madrid, 2014, p. 58.
} 
de los DESC. ${ }^{107}$ Por otra parte, estas mismas capacidades, cuando van complementadas con poderes administrativos de decisión, permiten sortear la crítica a la falta de legitimidad técnica o de experticia de los jueces para adjudicar conflictos sobre DESC. En efecto, la capacidad de integrar diversas fuentes de información, le permite a las INDHs ofrecer respuestas que se hagan cargo de los problemas estructurales que usualmente afectan el goce de derechos sociales y sortear las críticas acerca de la elitización de la justiciabilidad de los DESC. ${ }^{108}$ Además, las INDHs podrían desempeñar funciones relacionadas, como prestar asesoría técnica o realizar estudios en relación con los DESC, inclusive a petición de las autoridades o de otras instancias apropiadas; monitorear el cumplimiento de la normativa vigente y de las políticas públicas con los estándares internacionales de DESC; y, por último, como parte de sus atribuciones en materia de promoción de derechos humanos, las INDHs han comenzado a desempeñar roles en materia de estudios e informes que den cuenta de la vinculación entre el goce y ejercicio de los DESC con cuestiones relacionadas a políticas públicas sectoriales, como la planificación urbana, la regulación ambiental o la política tributaria. ${ }^{109}$

$\mathrm{Si}$ se compara las atribuciones que se reconocen usualmente a las defensorías de la región con aquellas que posee el INDH-CHI, advertimos que este último posee una fisionomía mucho más débil. Al menos formalmente, el INDH-CHI no posee facultades en relación con la investigación de quejas individuales. Lo mismo ocurre en relación con su legitimación activa. Al respecto, la ley entrega al INDH-CHI la legitimación para interponer acciones judiciales en el ámbito de su competencia, además de interponer querellas respecto de hechos que revistan carácter de crímenes de lesa humanidad o de guerra, tortura, desaparición forzada de personas, tráfico ilícito de migrantes o trata de personas. ${ }^{110} \mathrm{Si}$ bien el INDH-CHI efectúa una interpretación conforme a la cual este posee un mandato lo más amplio posible, de modo que el artículo 3 debe interpretarse como un listado meramente ejemplar, no taxativo, lo cierto es que alguna jurisprudencia le

\footnotetext{
${ }^{107}$ Kumar, cit. (n. 6), p. 292.

${ }^{108}$ Ferraz, Octavio, "Harming the poor through social rights litigation: lessons from Brazil", Texas Law Review, 2010, Vol. 89, № 7.

${ }^{109}$ KJERUM, Morten, National Human Rights Institution Implementing Human Rights, Danish Institute for Human Rights, Copenhagen, 2006, p. 14.

${ }^{110}$ Artículo 3 № 5 de la Ley 20.405.
} 
ha negado dicha legitimación activa respecto de hechos no comprendidos en el precepto. ${ }^{111}$ Más allá de estos problemas, el INDH-CHI ha demandado permanentemente una expansión de sus atribuciones que le permitan abordar la gran cantidad de solicitudes de protección y la necesidad de cubrir territorial y temáticamente los derechos humanos en una sociedad que atraviesa diversos conflictos.

\section{CONCLUSIONES Y PROPUESTA NORMATIVA}

Este artículo ha analizado las diversas cuestiones que pueden surgir en el proceso constituyente chileno a propósito de la eventual incorporación de una INDH en el texto constitucional. Después de una breve introducción al concepto y a los diferentes modelos de INDHs que existen en el mundo, y de una breve consideración acerca del potencial impacto del diseño institucional de las mismas, el artículo se enfocó en el modo en que la discusión sobre estas instituciones se ha ido progresivamente constitucionalizando. Posteriormente, se analizaron las razones que se pueden esgrimir para constitucionalizar su regulación, explicando las principales posibilidades regulatorias que se abren para su diseño institucional: modelo unipersonal o colegiado; concentración o fragmentación de instituciones; y discusiones generales sobre sus atribuciones.

El proceso constituyente chileno tiene la oportunidad de restaurar la confianza en las instituciones a través de un proceso inclusivo y participativo que es inédito en la historia del país. Por una parte, el proceso constituyente representa una oportunidad para reflexionar acerca de eventuales innovaciones institucionales que puedan hacer realidad las promesas contenidas en las normas sobre derechos humanos, debate en el que se enmarcan las preguntas sobre la institucionalidad de derechos humanos en el nuevo orden constitucional. Por la otra, sin embargo, la oportunidad de incorporar la regulación de esta institucionalidad en la nueva constitución supone enfrentar los desafíos o dilemas propios de la regulación constitucional, que a su vez dependen de la forma en que el nuevo orden constitucional aborde los procesos de reforma constitucional, al proceso político ordinario y la distribución de competencias entre distintos poderes.

${ }^{111}$ Aylwin, Coddou y Vial, cit. (n. 71), p. 53. 
En este escenario, que representa oportunidades y desafíos, la discusión constituyente sobre la nueva institucionalidad de derechos humanos debe considerar tanto las experiencias comparadas como cuestiones básicas de teoría constitucional, además de abordar críticamente las fortalezas y debilidades del actual INDH y de otras instituciones relacionadas. Considerando lo señalado hasta aquí, creemos que la regulación constitucional de la nueva INDH en Chile debería partir por dejar espacio a la configuración del diseño institucional por vía legislativa, pero sin renunciar a entregar ciertas orientaciones básicas al legislador a través de un conjunto de principios pertinentes. En lo que sigue, presentamos una propuesta de articulado y una breve justificación en línea con lo que se ha ido exponiendo en el cuerpo de este trabajo.

\section{Propuesta normativa}

Artículo único:

"El Instituto de Derechos Humanos es un órgano autónomo, con personalidad jurídica y patrimonio propio, que tiene por finalidad promover y proteger los derechos humanos de las personas que habiten en el territorio de Chile, establecidos en las normas constitucionales y legales; en los tratados internacionales suscritos y ratificados por Chile y que se encuentran vigentes, así como los emanados de los principios generales del derecho, reconocidos por la comunidad internacional (inc. $1^{\circ}$ ).

Excepcionalmente, promoverá y protegerá los derechos humanos de aquellas personas que, sin estar dentro del territorio nacional, sean susceptibles de ser afectados por acciones $u$ omisiones originadas en este (inc. $2^{\circ}$ )

La organización y atribuciones especiales del Instituto de Derechos Humanos serán determinados en una ley, que deberá seguir los principios de autonomía, pluralidad, experticia, coordinación y eficiencia en el desempeño de sus funciones (inc. $3^{\circ}$ )." 


\section{Breve justificación}

Se ha preferido la denominación "Instituto de Derechos Humanos" en vez de "Defensoría de los Pueblos" para evitar una regulación constitucional que prefigure una opción por un órgano unipersonal que se ha extendido en la región, y que incluye la protección del derecho a la buena administración. Al respecto, debe considerarse el eventual traslape de funciones que puede existir con las que ya desempeña la Contraloría General de la República o las atribuciones que eventualmente ésta pudiera asumir en el nuevo orden constitucional. En este sentido, proponemos que la nueva INDH no desempeñe funciones de supervisión del cumplimiento de deberes de administración o servicio público, o la realización de un eventual derecho de "buena administración". Por otra parte, se ha prescindido del adjetivo "nacional" para evitar cualquier problema que pueda existir por el reconocimiento de un Estado plurinacional que afecte la integración de los órganos estatales.

En cuanto a su objeto y atribuciones se reproduce parte de los artículos iniciales de la actual Ley 20.405 del INDH-CHI. De este modo, la nueva INDH debiera tener, como mínimo, la finalidad de promover y proteger los derechos humanos de las personas que habiten en el territorio de Chile, establecidos en las normas constitucionales y legales; en los tratados internacionales suscritos y ratificados por Chile y que se encuentran vigentes, así como los emanados de los principios generales del derecho, reconocidos por la comunidad internacional. Además, proponemos una regulación un tanto inédita a nivel constitucional comparado, que entregue a la nueva INDH obligaciones de promoción y protección de los derechos humanos de personas que, no encontrándose dentro del territorio chileno, puedan ser afectados por actividades originadas en Chile.

Se establece una serie de principios que deben informar las discusiones legislativas acerca del mejor diseño institucional del INDH, tomando en cuenta las fortalezas y debilidades del actual INDH-CHI. Referimos brevemente el alcance de cada uno de ellos.

i) Autonomía: considerado como un estándar internacional de carácter básico para las INDHs, esta supone una autonomía normativa, financiera e institucional. Como se dijo antes, este principio busca asegurar la estabilidad e independencia de la institución con respecto a los otros poderes del Estado, 
para lo cual el diseño institucional de los mecanismos de nombramiento de sus autoridades o formas de compensación que puedan gatillar la responsabilidad de las mismas es fundamental. La autonomía es la piedra angular de una INDH, en el entendido de que esta debe actuar como un vigilante de la administración pública y de los agentes estatales, razón por la cual precisa encontrarse libre de injerencias o interferencias para cumplir con su cometido. Pero no basta con una autonomía meramente formal. Su consecución precisa también de, entre otras cosas, un presupuesto adecuado y suficiente para asignar recursos según las prioridades definidas por la propia institución. Finalmente, es importante señalar que la articulación de la autonomía constitucional también puede quedar sujeta a una regulación común acerca de los mecanismos de nombramiento y regímenes de compensación de las denominadas "autonomías constitucionales".

ii) Pluralismo: otro de los estándares derivados de los "Principios de Paris" sostiene que las INDHs deben contemplar una composición pluralista, de modo que el nombramiento de sus órganos de dirección o de quienes conformen estos deben provenir de diferentes tipos de legitimidad, política, técnica y social. En este sentido, debe procurarse que la composición de la institución sea diversa, inclusiva y paritaria. Dicho de otro modo, la institución debe ser reflejo de la diversidad de nuestra sociedad, y de los grupos sociales, considerando factores territoriales, lingüísticos, culturales, religiosos, étnicos, etc. Lo anterior, permite generar vínculos más estrechos con la sociedad civil, lo que puede contribuir a la legitimidad de la institución $y$, en consecuencia, a su eficacia. Más allá de que la regulación opte por un diseño unipersonal o colegiado, la pluralidad debe expresarse ya sea en los mecanismos de nombramiento o en la composición de sus órganos o consejos directivos o consultivos.

iii) Experticia: otro de los principios fundamentales que deben observar las INDHs es la experticia o capacidad técnica tanto de sus órganos de dirección como de su planta funcionaria. En este sentido, una de las características fundamentales que observan aquellas INDHs que han desplegado con éxito sus funciones son aquellas que muestran equipos preparados y con experiencia en la promoción y protección de los derechos humanos. Por otra parte, se requiere el establecimiento de mecanismos de elección y designación de miembros que respondan a criterios técnicos y garanticen la independencia política, la integridad y la objetividad de la institución, sin dar especial favor a partidos políticos, facciones, secciones 
de la sociedad o grupos de interés que excluyan voces alternativas. Por otra parte, dichos mecanismos deben observar los principios de transparencia, probidad y participación ciudadana, que serán abordados por otras partes del texto constitucional.

iv) Coordinación: creemos que la coordinación obliga al legislador a considerar tanto la eficiencia en el despliegue de las funciones públicas, así como otra de las discusiones fundamentales y recientes a propósito del diseño institucional de las INDHs, esto es, el dilema de la fragmentación o concentración de funciones. La incorporación de este principio puede generar argumentos a favor de una concentración de funciones en un mismo organismo cuyo mandato queda fijado por la promoción y protección de los derechos humanos, independientemente del modelo institucional que adopte la nueva INDH.

\section{BIBLIOGRAFÍA CITADA}

\section{a) Doctrina}

Ackerman, John, Organismos autónomos y democracia: el caso de México, Siglo Veintiuno, México D.F, 2007.

Ackerman, Bruce; Ronsenkrantz, Carlos, "Tres concepciones de la democracia constitucional”, en: Ackerman, B.; Rosenkrantz, C.; Bouzat, Gabriel (dirs.), Fundamentos y alcances del control judicial de constitucionalidad, Centro de Estudios Institucionales, Buenos Aires, 1991.

Aguilar, Gonzalo; Steward, Rebecca, "El Defensor del Pueblo Latinoamericano como institución independiente de promoción y protección de los derechos humanos", Revista de Derecho Universidad Católica del Norte, 2008, año $15, \mathrm{~N}^{\mathrm{o}} 2$.

Atria, Fernando; Salgado, Constanza; Wilenmann, Javier, Democracia y neutralización: Origen, desarrollo y solución de la crisis constitucional, Lom Ediciones, Santiago, 2017.

Aylwin, José, Ombudsman y derechos indígenas en América Latina: estudio comparativo sobre el marco normativo e institucional, Instituto Interamericano de Derechos Humanos, San José, 2006, 846 p.

Aylwin, Vicente; Coddou, Alberto; Vial, Tomas, "El INDH y el estallido social", en: VARgAS, F. (Ed.), Informe Anual sobre Derechos Humanos en Chile, Ediciones UDP, Santiago, 2020.

BARKow, Rachel, "Insulating Agencies: Avoiding Capture Trough 
Institutional Design", Texas Law Review, 2010, Vol. 89, N 1, pp. 15-80.

Bianchi, Andrés, "La independencia del Banco Central de Chile: los años iniciales", en: Naudon, A.; Álvarez, L. (Eds.), 25 años de autonomía del Banco Central de Chile, Banco Central, Santiago, 2016.

Buck, Trevor; Birkham, Richard; Thompson, Brian, The Ombudsman enterprise and Administrative Justice, Ashgate, London, 2011.

Bulmer, Elliot, Instituciones reguladoras y de supervisión independientes (de la cuarta rama): Guía introductoria 19 para la Elaboración Constitucional, IDEA Internacional, Estocolmo, 2021.

Cardenas, Sonia, Chains of justice, University of Pennsylvania Press, Philadelphia, 2014.

CARver, Richard, "Performance \& Legitimacy: National Human Rights Institutions", International Council on Human Rights Policy, Ginebra, 2000.

CARver, Richard, "One NHRI or Many? How Many Institutions Does It Take to Protect Human Rights? - Lessons from the European Experience", Journal of Human Rights Practice, 2011, Vol 3, N 1, pp. 1-24.

Coddou, Alberto, "La institucionalidad de derechos humanos en Chile", en: VArgas, F. (Ed.), Informe Anual sobre Derechos Humanos en Chile, Ediciones UDP, Santiago, 2019.

Cole, Wade; Ramirez, Francisco, "Conditional Decoupling: Assessing the Impact of National Human Rights Institutions, 1981 to 2004”, American Sociological Review, 2013, Vol. 78, No 4.

Constenla, Carlos, Teoría y Práctica del Defensor del Pueblo, Editorial Reus, Madrid, 2010.

Courtney, Millina, "When Should We Put Anticorruption Agencies in the Constitution?", The Global Anticorruption Blog, 18 de Julio de 2016, https:// globalanticorruptionblog.com/2016/07/18/when-should-we-put-anticorruptionagencies-in-the-constitution/, consulta: 23 de marzo de 2021.

De Witte, Bruno, "National Equality Institutions and the domestication of EU Non-Discrimination Law", Maastricht Journal of European and Comparative Law, 2011, Vol. 18.

DodD, Lynda, "Reassessing the Rights Revolution", en: DodD, L (Ed.), The rights revolution revisited: Institutional perspectives on the private enforcement of civil rights in the US, Cambridge University Press, Cambridge, 2018.

FerradA, Juan Carlos, "Autonomía como técnica de reparto de potestades públicas: El caso del Banco Central de Chile", Revista Chilena de Derecho, 1998, Número Especial, pp. 335-344.

Ferraz, Octavio, "Harming the poor through social rights litigation: lessons from Brazil.", Texas Law Review, 2010, Vol. 89, № 7, pp. 1643-1668.

FrAHM, Michael, Australasia and Pacific Ombudsman Institutions: Mandates, Competences and Good Practice, Springer, Vienna, 2013. 
JimÉNEZ, Guillermo, "Nonjudicial administrative justice in Latin America; a case study of the Chilean comptroller-general", Tesis doctoral, University College of London, 2018.

KJÆRUM, Morten, National Human Rights Institution Implementing Human Rights, Danish Institute for Human Rights, Copenhague, 2006.

Kelsen, Hans, "La garantía jurisdiccional de la Constitución", Revista Iberoamericana de Derecho Procesal Constitucional, 2008, № 10.

KING, Jeff, "Constitutions as Mission Statements", en: Galligan, D.; Versteeg, M. (Eds.), Social and political foundations of constitutions, Cambridge University Press, New York, 2013.

Komesar, Neil, Imperfect Alternatives, University of Chicago Press, Chicago, 1994.

Kosztolanyi, Gusztav, "An Ombudsman to Protect Us", Central Europe Review, 2001, Vol. 24, No 3 .

Kuckso-Stadlmeyer, Gabriele (Ed.), European Ombudsman-Institutions: $A$ comparative analysis regarding the multifaceted realisation of an idea, Springer, Vienna, 2008.

Kumar, Raj, "National Human Rights Institutions: Good Governance Perspectives on Institutionalization of Human Rights", American University International Law Review, 2003, Vol. 19, № 2.

Lovera, Domingo "Institucionalidad de Derechos Humanos en Chile", en Navia, C.; De la MaZA, A. (Eds.), Seminario Internacional: "Institucionalidad de Derechos Humanos: Desafios para su creación e implementación”, INDH, Centro de Derechos Humanos UDP, Santiago, 2016.

Linos, Katerina; PEGRAM, Tom, "What works in human rights institutions?", American Journal of International Law, 2017, Vol. 111, N 3.

Linos, Katerina; PEgRAM, Tom, Interrogating form and function: designing effective national human rights institutions, The Danish Institute for Human Rights, Copenhague, 2015.

Linos, Katerina; PEgram, Tom, "The language of compromise in international agreements", International Organization, Vol. 70, №3.

Livingstone, Stephen; Murray, Rachel, "The effectiveness of National Human Rights Institutions", en: Halliday, S.; Schmidt, P. (Eds.), Human Rights Brought Home: Socio-legal perspectives on Human Rights in The National Context, Hart Publishing, Portland, 2004.

Mc LeAn, Janet; Tushnet, Mark, "Administrative bureaucracy”, en: TushnET, M.; Fleiner, T.: Saunders, C. (Eds.), Routledge handbook of constitutional law, Routledge, Londres - Nueva York, 2013.

Mertus, Julie, The United Nations and Human Rights: A guide for a new era, Routledge, Nueva York, 2009.

Milos, Domingo Juan, "Un defensor del pueblo para Chile”, Perspectivas en 
política económica y gestión, 1999, Vol. 3, No 1, pp. 231-254.

Miranda, Fabiola; Andrade, Carlos, "Entrevista: Patricia Muñoz, Defensora de la Niñez", Revista del Departamento de Trabajo Social Universidad Alberto Hurtado, 2020, Vol. 10, N 1, pp. 119-133.

Moure, Ana María, El Ombudsman: un estudio de derecho comparado con especial referencia a Chile, Dykinson, Madrid, 2014.

Murillo, Victoria; LeVISTKY, Steven; Brinks, Daniel, La Ley y la trampa en América Latina: por qué optar por el debilitamiento institucional puede ser una estrategia política, Siglo veintiuno, México D.F, 2021.

NAsH, Claudio, “A propósito del affaire Micco: ¿Llegó el momento de discutir a fondo la institucionalidad de derechos humanos en Chile?", 2020, https://www. ciperchile.cl/2020/05/09/a-proposito-del-affaire-micco-llego-el-momento-dediscutir-a-fondo-la-institucionalidad-de-derechos-humanos-en-chile/, consulta: 13 de julio de 2021.

NARAnjo, Mónica "Derechos de la naturaleza y la gestión de la defensoría del pueblo de ecuador", Tesis de máster en derecho, FLACSO, Quito, 2016.

Nogueira, Humberto, “Un enfoque Constitucional”, en Ministerio Secretaría General de la Presidencia (Eds.) El Defensor ciudadano que queremos. Proyecto de Reforma y Modernización del Estado, Gobierno de Chile, Santiago, 2001.

O’Cinneide, Colm, "A Single Equality Body: Lessons from Abroad", Working Paper Series N4., Equal Opportunities Commission, London, 2002,

PARDOw, Diego, “¿Control o autonomía? El debate sobre agencias regulatorias independientes", Revista de Derecho (Valdivia), 2018, Vol. 31, № 2.

PEAGRAm, Thomas, "National human rights institutions in Latin America: Politics and institutionalization", en: Goodman, R.; Peagram, T. (Eds.), Human Rights, State, Compliance, and Social Change: Assessing National Human Rights Institutions, Cambridge University Press, New York, 2012.

Pinheiro, Paulo; Baluarte, David, "National strategies - Human Rights Commissions, Ombudsman and National Action Plans", Human Development Reports, 2000, pp. 1-36.

RavetLlat, Isaac, "El Defensor de los derechos de la niñez en Chile: Hacia un verdadero garante de su interés superior", Estudios Constitucionales, 2017, Vol. $15, \mathrm{~N}^{\mathrm{o}} 1$.

REIF, Linda, The ombudsman, Good Governance and the International Human Rights System, Springer, Leiden, 2004.

Schmitr, Carl, Teoría de la Constitución, Alianza, Madrid, 1982.

Tushnet, Mark, "Institutions Protecting Constitutional Democracy: Some conceptual and methodological preliminaries", University of Toronto Law Journal, 2020, Vol. 70, Nº 2 .

Valenzuela, Ester; Correa, Paula "Derechos humanos de niños, niñas y adolescentes. Infancia primero: lo prometido es deuda", en: VARGAS, F. (Ed.), 
Informe Anual sobre Derechos Humanos en Chile 2019, Ediciones UDP, Santiago, 2019.

Valladares, Leo, "El Ombudsman como canal de acceso a la justicia", Revista Instituto Interamericano de Derechos Humanos, 2001, Vol. 32-33, pp. 3558.

b) Normativa citada

Ley Orgánica de la Defensoría del Pueblo de 2019. (Ecuador).

Ley 20.405, de 2009.

Principios de Paris, 1993.

Directiva 2002/73/EC (UE)

Equality Act 2006. (Reino Unido).

c) Otras fuentes

Actas de la Comisión Ortúzar, Sesión No 399, 12 de Julio de 1978, pp. 645654, https:/www.bcn.cl/lc/cpolitica/actas_oficiales-r, consulta: 14 de enero de 2021.

Defensoría de la NiÑEz (eds.), "Informe Anual 2021: Derechos humanos de niños, niñas y adolescentes en Chile", Defensoría de los derechos de la Niñez, Santiago, 2021.

European Union Agency for Fundamental Rights, "Strong and Effective National Human Rights Institutions: challenges, promising practices and opportunities", 2020, https://fra.europa.eu/en/publication/2020/strong-effectivenhris

GANHRI, Observaciones generales del Subcomité de Acreditación, 21 de febrero de 2018, https://www.ohchr.org/Documents/Countries/NHRI/GANHRI/ SP_GeneralObservations_Revisions_adopted_21.02.2018_vf.pdf, consultada: 13 de marzo de 2021

Instituto Nacional de Derechos Humanos, "Informe de Resultados: Encuesta Nacional de Derechos Humanos 2020”, 2020, https://www.indh.cl/bb/wp-content/ uploads/2021/06/Encuesta-Nacional-de-DDHH-2020.pdf, consultada: 12 de julio de 2021.

Resolución de la Asamblea General de las Naciones Unidas, A/RES/48/134, "Anexo: Principios relativos al estatuto de las instituciones nacionales", 20 de diciembre de 1993.

Resolución 5/1 del Consejo de Derechos Humanos, A/HRC/RES/5/, 18 de junio de 2007, consultada: 14 mayo de 2020.

Resolución de la Asamblea General de las Naciones Unidas, A/74/226, 25 de julio de 2019, https://undocs.org/pdf?symbol=es/A/74/226, consultada: 8 de abril de 2021.

Declaración de Nairobi: Novena Conferencia Internacional de Instituciones 
Nacionales para la Promoción y Protección de los Derechos Humanos, Nairobi, octubre de 2008. https://ohchr.org/Documents/Countries/NairobiDeclarationSp. pdf, consultada: 8 de abril de 2021 .

Observaciones finales sobre los informes periódicos cuarto y quinto combinados de Chile, CRC/C/CHL/CO/4-5, Comité de los Derechos del Niño, octubre de 2015, https://tbinternet.ohchr.org/_layouts/15/treatybody external/Download.aspx?symbolno= $\mathrm{CRC} / \mathrm{C} / \mathrm{CHL} / \mathrm{CO} / 4-5 \& \mathrm{Lang}=\mathrm{Sp}$

Observación General №2, CRC/GC/2002/2, Comité de los Derechos del Niño, noviembre de 2002, http://docstore.ohchr.org/SelfServices/FilesHandler. ashx? enc $=6$ QkG1d\%2FPPRiCAqhKb7yhsiQq18gX5Zxh0cQqSRzx6ZcNR3 Y dFwaRoLFkDFvNRIVoZv3aKcWqVarwlCH6wwd4LR5MI72oklbmnVFtku3\% 2B01xRgfOF\%2BSAWIf3asQH\%2FxDOW

Programa de las Naciones Unidas para el Desarrollo (PNUD); Oficina del Alto Comisionado de las Naciones Unidas para los Derechos Humanos (ACNUDH), "UNDP-OHCHR Toolkit for collaboration with National Human Rights Institutions", 2010, https://www.ohchr.org/Documents/Countries/NHRI/1950-UNDP-UHCHRToolkit-LR.pdf, consultada: 15 de julio de 2020. 